\title{
One, Two, Many - Insensitivity to Group Size in Games with Concentrated Benefits and Dispersed Costs
}

\author{
Heiner Schumacher* Iris Kesternich $^{\dagger}$ \\ Michael Kosfeld Joachim Winter $^{\S}$
}

June 14, 2016

\begin{abstract}
We experimentally analyze distributional preferences when a decider chooses the provision of a good that benefits herself or a receiver, and creates costs for a group of payers. The treatment variation is the number of payers. We observe that subjects provide the good even if there are many payers so that the costs of provision exceed the benefits by far. This result holds regardless of whether the provision increases the decider's payoff or not. Intriguingly, it is not only selfish or maximin types who provide the good. Rather, we show that a substantial fraction of subjects are "insensitive to group size": they reveal to care about the payoff of all parties, but attach the same weight to small and large groups so that they ignore large provision costs that are dispersed among many payers. Our results have important consequences for the approval of policies with concentrated benefits and large, dispersed cost, as well as the analysis of ethical behavior, medical decision making, and charity donations.
\end{abstract}

Keywords: Social Preferences, Distribution Games, Concentrated Benefits and Dispersed Costs, Insensitivity to Group Size

JEL Classification: C91, D63, H00

\footnotetext{
*KU Leuven, heiner.schumacher@kuleuven.be.

${ }^{\dagger} \mathrm{KU}$ Leuven, iris.kesternich@kuleuven.be.

${ }^{\ddagger}$ Corresponding Author. Goethe University Frankfurt, Theodor-W.-Adorno-Platz 4, 60323 Frankfurt am Main, Germany, +49 69798 34823, kosfeld@econ.uni-frankfurt.de.

§University of Munich, winter@lmu.de.
} 
Acknowledgments. Earlier versions of this paper were circulated under the title "Us and Them: Distributional Preferences in Small and Large Groups." This research has profited from financial support by the DFG through SFB-Transregio 15. Heiner Schumacher acknowledges support from the Vereinigung von Freunden und Förderern der Johann Wolfgang Goethe-Universität Frankfurt am Main e.V.; Iris Kesternich acknowledges support from Unicredit \& Universities; Michael Kosfeld acknowledges support from the Alfons und Gertrud Kassel-Stiftung. We would like to thank Alexander Cappelen, Geert Dhaene, Dirk Engelmann, Raymond Fisman, Guido Friebel, Marc Fleurbaey, Christina Gravert, Martin Kocher, Henry Mak, Petra Nieken, Jawwad Noor, Maximilian Rueger, Larry Samuelson, Klaus Schmidt, Bertil Tungodden, Joergen Weibull and Nick Zubanov as well as seminar audiences at the CESifo Conferences on Empirical Health Economics and Behavioral Economics, European Economic Association Annual Meeting 2013, Bergen School of Economics, Boston University, Hamburg Center for Health Economics, Harvard Health Care Policy, Indiana University Bloomington, IUPUI, Marburg University, University of Michigan Ann Arbor and University of Stirling for valuable comments and discussions. We thank Suzan Elshout and the team of programmers at CentERdata Tilburg. We thank Marc Rummel, Rene Cyranek, David Schindler and the whole FLEX and MELESSA teams for their support. We thank Hendrik Brackmann and Kevin Kloiber for excellent research assistance. The usual disclaimer applies. 


\section{Introduction}

In many domains, an agent's decisions create both benefits for a small, well-defined group and costs that are dispersed among many individuals. For example, when a politician decides about a policy that is favored by a special interest group, she has to weigh the benefits for this group against the costs that the policy creates for the general public. When a physician determines a patient's treatment, she affects not only the patient's well-being, but also the treatment costs that the insurance company (and hence the group of customers of this company) has to pay. Individuals engaged in illegal behaviors, such as tax evasion or corruption, typically redistribute income to themselves or their families at the expense of the larger society.

To analyze these choices, economists need to know how agents trade off concentrated benefits against dispersed costs. Most theoretical work in economics on political and medical decision making, tax evasion or corruption assumes perfectly selfish agents. However, many economists will agree that the assumption of pure selfishness is often made mainly for simplicity. There is substantial evidence that a majority of individuals do not act in a completely selfish manner when making decisions that affect the payoff of others. ${ }^{1}$ One robust finding from the lab is that many individuals take into account the welfare of others and have a preference for efficient outcomes (Andreoni and Miller 2002, Charness and Rabin 2002, Engelmann and Strobel 2004, Fisman et al. 2007, 2014, 2015). Yet, the experimental games in this literature are typically played in small groups of only two or three players. It is unclear what distributional preferences look like when the costs of an action are large but dispersed among many individuals.

What matters is the extent to which decision makers take into account the number of people who are affected by their decision. Consider an individual who values the payoff of a single person, but ignores the size of an affected group. This individual may give generously in dictator games, but at the same time redistribute resources from many to herself if her benefit is sufficiently large relative to the costs per person. Thus, an individual may act both generously and selfishly, depending on the degree of cost dispersion and the extent to which she takes into account the number of payers. Next, consider an individual who is concerned with welfare in dictator games, i.e., she gives a lot if the receiver's benefit exceeds the costs of giving and little otherwise. If she ignores the size of an affected group, she may also redistribute resources from many to few even if the costs of redistribution exceed the benefits by far. Thus, an individual may care both about welfare and equality, depending on the degree of cost dispersion and the shape of her preferences. These examples illustrate that it is difficult to extrapolate behavior in dictator games to situations in which decisions affect many individuals as long as we do

\footnotetext{
${ }^{1}$ See, for example, Fehr and Schmidt (2006) for a review of the experimental evidence.
} 
not know how sensitive or insensitive decision makers are with respect to the size of an affected group. This poses an open empirical question which we address in this paper.

We conduct an experiment to study distributional preferences in generalized dictator games with concentrated benefits and dispersed costs. In each game, a decider chooses the provision of a good which potentially affects her payoff, the payoff of a single receiver, and the payoff of $n$ payers. Some games are standard dictator games between the decider and the receiver, i.e., the payers' payoff is fixed. In the remaining games, the provision of the good increases the decider's or the receiver's payoff, or both, while the $n$ payers pay for it. We call these games dispersed costs games. In dispersed costs games with decider benefit, the provision of the good only benefits the decider at the expense of the payers; in dispersed costs games with receiver benefit, the provision of the good benefits only the receiver while the payers pay for it. Our treatment variation is the number of payers, with values $n \in\{1,4,8,16,32\}$. For each game, we keep the costs per payer constant across treatments, so that increasing the number of payers implies increasing costs of provision. This allows us to analyze distributional preferences when the costs of provision by far exceed its benefits.

To derive testable predictions for behavior in dispersed costs games, we generalize Andreoni and Miller's (2002) CES utility function. Our model captures two different modes in which an individual may or may not take into account the number of payers $n$. A decider is d-insensitive to group size if she provides the good in a dispersed costs game with decider benefit, regardless of $n$, whenever the costs per payer are small enough relative to the decider's benefit. And a decider is $r$-insensitive to group size if she provides the good in a dispersed costs game with receiver benefit, regardless of $n$, whenever the costs per payer are small enough relative to the receiver's benefit. Accordingly, a decider is $d$-sensitive ( $r$-sensitive) to group size if she stops providing the good in a dispersed costs game with decider (receiver) benefit if the number of payers is sufficiently large. Deciders can be both $d$-insensitive and $r$-sensitive to group size or vice versa. Purely selfish types are by definition $d$-insensitive to group size; and pure maximin types are by definition $r$-insensitive to group size. Deciders who are not purely selfish or pure maximin types ("non-pure" types) may be sensitive or insensitive to group size..$^{2}{ }^{3}$

If all subjects with non-pure preferences were $d$ - and $r$-sensitive to group size, we should observe that they stop providing the good in dispersed costs games as the number of payers increases. This is not what we find in our experiment. In all games and treatments, the majority of subjects provide significant amounts of the good, thereby

\footnotetext{
${ }^{2}$ Throughout, "(in)sensitivity to group size" means " $d$ - and/or $r$-(in)sensitivity to group size."

${ }^{3}$ The social preference models by Fehr and Schmidt (1999), Bolton and Ockenfels (2000), and Charness and Rabin (2002) also make precise predictions for our dispersed costs games. In the Appendix, we show that none of them captures $d$ - and $r$-insensitivity to group size for generic parameter values.
} 
reducing the overall group payoff substantially. For example, subjects provide on average 5.72 units (10 being the maximum) in a game in which each unit provided creates a benefit of one token for both the decider and the receiver, but also costs of one token for each of 32 payers. Intriguingly, this result is not exclusively driven by pure (either selfish or maximin) types, but by non-pure types who reveal to care about the payoff of all parties. These subjects provide the same amount in treatments with either a small group or a large group of payers. Also their share does not differ significantly between treatments. This pattern allows us to provide a conservative lower bound of 37.1 percent on the share of subjects exhibiting $d$-insensitivity to group size, and a lower bound of 37.6 percent on the share of subjects exhibiting $r$-insensitivity to group size (the estimated correlation is 0.63$)$. These subjects take into account the payoffs of all parties, but as they ignore the number of payers (in one way or another), they choose actions that have a detrimental effect on overall welfare.

We also see reversals in behavior as described in the examples above: 24 percent of the subjects who give most generously in dictator games also take the maximal amount from payers in a game with large, dispersed costs. Importantly, the fact that a subject is concerned with welfare in dictator games - she gives a lot if the receiver's benefits exceed the costs and little otherwise - is not informative about her behavior when the costs are dispersed. Those with the highest degree of welfare concerns in dictator games just provide as much in a game with large, dispersed costs as the rest. These results show that subjects' behavior in situations with concentrated benefits and dispersed costs may be quite different from behavior in standard dictator games.

Together, our theoretical and experimental findings provide a new explanation for a number of important empirical patterns (see Section 7 for a detailed discussion). In particular, they suggest that many people may approve of political or economic decisions which create benefits for a few but at the same time entail large costs for society (such as collective action of small occupation groups). A classic argument in the literature is that small groups are more successful in achieving their common interests through lobbying than large groups, because they are better able to overcome the free-rider problem (Olson 1965). Our results indicate that unaffected third parties (such as politicians, judges, or voters) may already be positively inclined towards policies with concentrated benefits and large, dispersed costs. Thus, lobbying might not even be necessary to implement them. Further implications of our results are that charity donations to clearly specified individuals can go hand in hand with tax evasion; physicians recommend health treatments depending on whether the patient is insured or pays for herself; and that altruism is fully congestible, i.e., donations benefiting a single recipient may be large but only very small or even zero when they are distributed among many.

The rest of the paper is structured as follows. In the next section, we discuss the 
related literature. In Section 3, we develop a social preference model that captures sensitivity and insensitivity to group size in generalized dictator games. Section 4 describes the experimental setup and Section 5 explains the results. In Section 6, we discuss various mechanisms that may cause insensitivity to group size. In Section 7, we examine the key economic implications of our findings. Finally, Section 8 concludes.

\section{Related Literature}

Our paper is related to different strands in the literature, which we discuss in this section.

Distributional Preferences. Seminal work by Andreoni and Miller (2002) shows that giving in dictator games can be rationalized by economic preferences. They as well as many subsequent papers demonstrate that subjects are heterogeneous with respect to their distributional preferences in allocation games: some are selfish, others maximize the payoff of the least well-off individual, or group welfare. $4^{4}$ We advance this literature by analyzing the extent to which distributional preferences depend on the size of a group that is affected by a subject's decision. This is important, because costs are dispersed in many domains in which individuals make distribution decisions. We show that information about behavior in simple dictator games may not allow us to draw conclusions about distributional preferences in situations with concentrated benefits and dispersed costs. A subject who gives generously in dictator games but ignores the number of payers may act very selfishly when the costs of taking are dispersed among sufficiently many individuals.

Closest to ours is Andreoni (2007) who studies giving in a dictator game with varying numbers of receivers. He finds that the average decider takes into account the number of receivers, although at a decreasing rate. We find that many subjects who are not purely selfish or pure maximin types ignore the number of payers, and that the occurrence of this phenomenon does not depend on whether their choices affect their own payoff or not. An important difference to Andreoni's (2007) design is that each subject in our experiment is confronted only with one group size. Thus, we can rule out demand effects that may otherwise prompt subjects to react to varying numbers of payers.

Contingent Valuation. Insensitivity to group size is reminiscent of what has been called "extension neglect" in the contingent valuation literature $5^{5}$ Kahneman et al. (1999) define extension neglect as follows: "The attitude to a set of similar objects is often determined by the [...] valuation of a prototypical member of that set. [...] Unless attention is specifically directed to it, the size of the set has little or no influence on

\footnotetext{
${ }^{4}$ See Charness and Rabin (2002), Engelmann and Strobel (2004), Fisman et al. (2007, 2014, 2015).

${ }^{5}$ Contingent valuation is a method used to estimate the willingness-to-pay for particular public goods, typically from survey data. See Carson (2012) and Hausman (2012) for a recent critical discussion.
} 
its valuation." A classic study is Desvousges et al. (1993) who describe the following hypothetical situation to their subjects: "[2,000, or 20,000, or 200,000] migrating birds die each year by drowning in uncovered oil ponds, which the birds mistake for bodies of water. These deaths could be prevented by covering the oil ponds with nets. How much money would you be willing to pay to provide the needed nets?" Subjects were found to be largely insensitive to the scope of the problem. The average stated willingness to pay was 80 USD, 78 USD and 88 USD, respectively.6 Our results highlight a phenomenon that appears similar to extension neglect in the context of allocation decisions with dispersed costs. However, the main objective of our paper is fundamentally different from the contingent valuation literature.

First, contingent valuation is primarily interested in the elicitation of passive valuations for a good that respondents will never use and whose valuations cannot be revealed through market choices (Carson 2012). In fact, as Kahneman et al. (1999) write, the main objective of the literature "is far from the core of economic discourse", a view that is also corroborated by the fact that most of the results have not entered the economic debate up to now. In contrast, the key interest of our paper lies exactly in the economic analysis. We study real, incentivized allocation decisions and identify two different types of insensitivity to group size in distributional preferences. Second, Desvousges et al. (1993) and others typically consider very large numbers of beneficiaries (e.g., 2,000 to 200,000). In contrast, the number of payers in our dispersed costs games is at most 32 . While the group sizes we consider are relatively large compared to most experimental games analyzed in the economic literature, they are cognitively much less demanding than the numbers encountered in the contingent valuation literature. Our results thus show that insensitivity to group size starts at comparatively small numbers. Third, our paper also has very different applications in mind, all of them being at the core of the economic discourse, e.g., the provision of health care, local public goods, or tax evasion.

Part-Whole Bias. So far, the only experimental paper in economics that draws on findings from the contingent valuation literature is Bateman et al. (1997). The authors document a so-called "part-whole bias" in choices over private goods: the sum of elicited valuations of two complementary private goods is larger when evaluated separately than when evaluated as a bundle, a finding that poses a problem to Hicksean consumer theory. Besides a methodological overlap stemming from the fact that Bateman et al. (1997) also use non-hypothetical decisions with real money at stake, there is no further relationship to the main question and analysis of our paper.

Psychic Numbing. The psychological literature on "psychic numbing" is related to our paper. The term "psychic numbing" is due to Lifton (1967) and describes a human

\footnotetext{
${ }^{6}$ See also Frederick and Fischhoff (1998) and Kahneman (2003, 2011).
} 
tendency to ignore or withdraw attention from certain negative experiences or future consequences. Most of the work on psychic numbing has focused on human or natural disasters, such as the Hiroshima bombing in World War II, and the association with post-traumatic stress disorders (e.g., Slovic 2007). The main focus of this literature is again quite different from our paper. Similar to contingent valuation, most of the cases and arguments consider very large numbers of individuals who are affected (e.g., whole populations). In contrast, numbers in our setup are much smaller and easier to handle cognitively. Further, the objective of this literature is not to integrate or formalize the notion of psychic numbing in an economic model. Again, writers see the phenomenon as something that is rather outside the classic economic framework. In contrast, our contribution is to develop and analyze an economic utility model that helps improve our understanding of distributional preferences in important real-world situations with concentrated benefits and dispersed costs.

Third-Party Neglect. A number of papers find that when two parties interact strategically, the welfare of a third party may be neglected. Güth and van Damme (1998) study bargaining games in which the proposer suggests a split between himself, a receiver who has to approve the allocation, and a passive bystander. They show that the passive bystander usually receives very little in this setting. Okada and Riedl (2005) analyze bargaining games in which the proposer first chooses the number of receivers (either one or two) and then how to distribute the endowment within the group. The proposal is implemented if all chosen receivers accept. Proposers correctly anticipate that with two receivers they would have to share a larger fraction to get acceptance. Thus, a majority opts for one receiver only, leaving the other receiver with the value of the outside option. In both papers, the observed "third-party neglect" is a result of strategic interaction. In contrast, strategic concerns are absent in our setup. The resulting phenomenon is entirely driven by subjects' revealed distributional preferences.

Group Size Effects in Public Goods Provision. Finally, there is an experimental literature on group size effects in public goods games; see, e.g., Isaac and Walker (1988) and Isaac et al. (1994). The main motivation is to test Olson's (1965) conjecture that small groups are more successful in establishing mutual cooperation than large groups. As in the literature on third-party neglect, the main focus is on strategic concerns. These papers examine repeated interaction between group members so that reputation concerns additionally come into play. In consequence, their results do not allow us to draw conclusions about the shape of distributional preferences in situations with concentrated benefits and dispersed costs. 


\section{A Theory of Distributional Preferences in Small and Large Groups}

This section develops a formal framework to analyze a decision maker's choices in generalized dictator games. These games involve three parties: a decider, a receiver, and $n$ payers. In each game, the decider chooses the provision $x \in[0, \bar{x}]$ of a good. The decider's payoff is $\pi_{D}(x)=W_{D}+a x$, the receiver's payoff is $\pi_{R}(x)=W_{R}+b x$, and each payer's payoff is $\pi_{P}(x)=W_{P}-c x$. Hence, each game is characterized by the parameters $(a, b, c)$ and the number of payers $n$. Games with $a<0, b>0$ and $c=0$ are dictator games; games with $a>0, b=0$ and $c>0$ are called dispersed costs games with decider benefit; games with $a=0, b>0$ and $c>0$ are called dispersed costs games with receiver benefit; and games with $a>0, b>0$ and $c>0$ are called dispersed costs games with decider and receiver benefit. Throughout, we assume $W_{D}=W_{P}>W_{R}$.

\subsection{Dictator Games}

A robust finding in dictator games is that subjects' behavior is heterogeneous (e.g., Engel 2011). Andreoni and Miller (2002) capture this heterogeneity in the CES utility function 7

$$
U^{A M}\left(\pi_{D}, \pi_{R}\right)=\left(\alpha \pi_{D}^{\rho}+(1-\alpha) \pi_{R}^{\rho}\right)^{1 / \rho}
$$

The parameter $\alpha$ represents the weight of the own payoff relative to the receiver's payoff; the parameter $\rho$ defines the convexity of the utility function. This CES utility function captures the three "pure" social preference types: the purely selfish type has $\alpha=1$; the pure welfare type has $\alpha=0.5$ and $\rho=1$; and the pure maximin type has $\alpha=0.5$ and $\rho \rightarrow-\infty$.

Define $\theta=(1-\alpha) / \alpha$. In a dictator game, a subject whose preferences can be described by $U^{A M}$ will provide $x \in(0, \bar{x})$ units if the marginal rate of substitution between the decider's and the receiver's payoff at $x$ equals the inverse "price of giving",

$$
M R S_{D R}(x) \equiv \frac{1}{\theta}\left(\frac{\pi_{R}(x)}{\pi_{D}(x)}\right)^{1-\rho}=-\frac{b}{a} .
$$

She does not provide anything if $M R S_{D R}(0) \geq-b / a$, and the maximal amount if $M R S_{D R}(\bar{x}) \leq-b / a$. How would this subject behave in our dispersed costs games? The answer depends on the extent to which the subject takes into account the number of payers. To capture the various possibilities, we have to extend $U^{A M}$.

\footnotetext{
${ }^{7}$ See also Andreoni (2007), Cox et al. (2007), Fisman et al. (2007, 2014, 2015), Cox and Sadiraj (2012).
} 


\subsection{Dispersed Costs Games}

We generalize Andreoni and Miller's (2002) utility function by including another party, the payers, and by letting the utility weights of the receiver's and the payers' payoff depend on the number of payers $n$. The CES utility function then becomes

$$
U\left(\pi_{D}, \pi_{R}, \pi_{P}, n\right)=\left(\pi_{D}^{\rho}+g(n) \pi_{R}^{\rho}+f(n) \pi_{P}^{\rho}\right)^{\frac{1}{\rho}} .
$$

The function $g(n)$ captures the weight of the receiver's payoff when there are $n$ payers affected by the decider's action. Similarly, $f(n)$ is the weight of a single payer's payoff as a function of the number of payers. Both functions are needed to describe behavior in dispersed costs games. We normalize $g(0)=\theta$ and $f(0)=0$ so that for dictator games the utility function collapses to a monotone transformation of $U^{A M}$. For future reference we define $h(n)=f(n) / g(n)$ whenever this ratio exists.

Our CES utility function again captures the three pure preference types. ${ }^{8}$ Note that both the purely selfish type with utility function $U\left(\pi_{D}, \pi_{R}, \pi_{P}, n\right)=\pi_{D}$ and the pure maximin type with utility function $U\left(\pi_{D}, \pi_{R}, \pi_{P}, n\right)=\min \left\{\pi_{D}, \pi_{R}, \pi_{P}\right\}$ ignore the number $n$ of payers. The pure welfare type with utility function $U\left(\pi_{D}, \pi_{R}, \pi_{P}, n\right)=$ $\pi_{D}+\pi_{R}+n \pi_{P}$ takes the number of payers into account. We say that an agent has "non-pure" social preferences if she does not belong to the class of pure preference types. In the following, we assume that agents with non-pure preferences value the payoff of each party, and the weight attached to a group of payers does not strictly decrease in the size of the group. Formally, this is the case if $1>\rho>-\infty, f(n)$ and $h(n)$ weakly increase in $n$, and $\theta, h(1)>0$.

The value $g(0)=\theta$ defines the marginal rate of substitution between the decider's and the receiver's payoff. Thus, the first-order condition in (2) again characterizes behavior in dictator games. The utility weight $f(n)$ defines the marginal rate of substitution between the decider's and a payer's payoff. In a dispersed costs game with decider benefit, an individual whose preferences can be described by $U$ provides $x \in(0, \bar{x})$ units if

$$
M R S_{D P}(x) \equiv \frac{1}{f(n)}\left(\frac{\pi_{P}(x)}{\pi_{D}(x)}\right)^{1-\rho}=\frac{c}{a} .
$$

She does not provide anything of the good if $M R S_{D P}(0) \leq c / a$, and the maximal amount if $M R S_{D P}(\bar{x}) \geq c / a$. The provision of the good decreases in $f(n)$. Consider Figure 1 below. If a decider with non-pure social preferences always takes into account the number of payers, the indifference curves in the $\pi_{D}-\pi_{P}$ space become flat as $n \rightarrow \infty$ (see the left graph). In this case, $f(n) \rightarrow \infty$ for $n \rightarrow \infty$. Intuitively, this means that the decider's

\footnotetext{
${ }^{8}$ The purely selfish type has $\theta=g(n)=f(n)=0$ for all $n$; the pure welfare type has $\rho=1$, $\theta=g(n)=1$ and $f(n)=n$ for all $n$; and the pure maximin type has $\rho \rightarrow-\infty, \theta=g(n)=1$ for all $n$ and $f(n)=1$ for all $n \geq 1$.
} 
own payoff $\pi_{D}$ becomes unimportant relative to a payer's payoff $\pi_{P}$ when there are more and more payers. However, if a decider with non-pure preferences does not fully take into account the number of payers, i.e., $f(n)$ converges to some finite value for $n \rightarrow \infty$, then for any payoff combination the slope of the indifference curves remains above some positive level (see the right graph). The decider then provides some of the good when the ratio $c / a$ is close enough to zero, regardless of the number of payers.

Figure 1: Indifference curves in the $\pi_{D}-\pi_{P}$ space
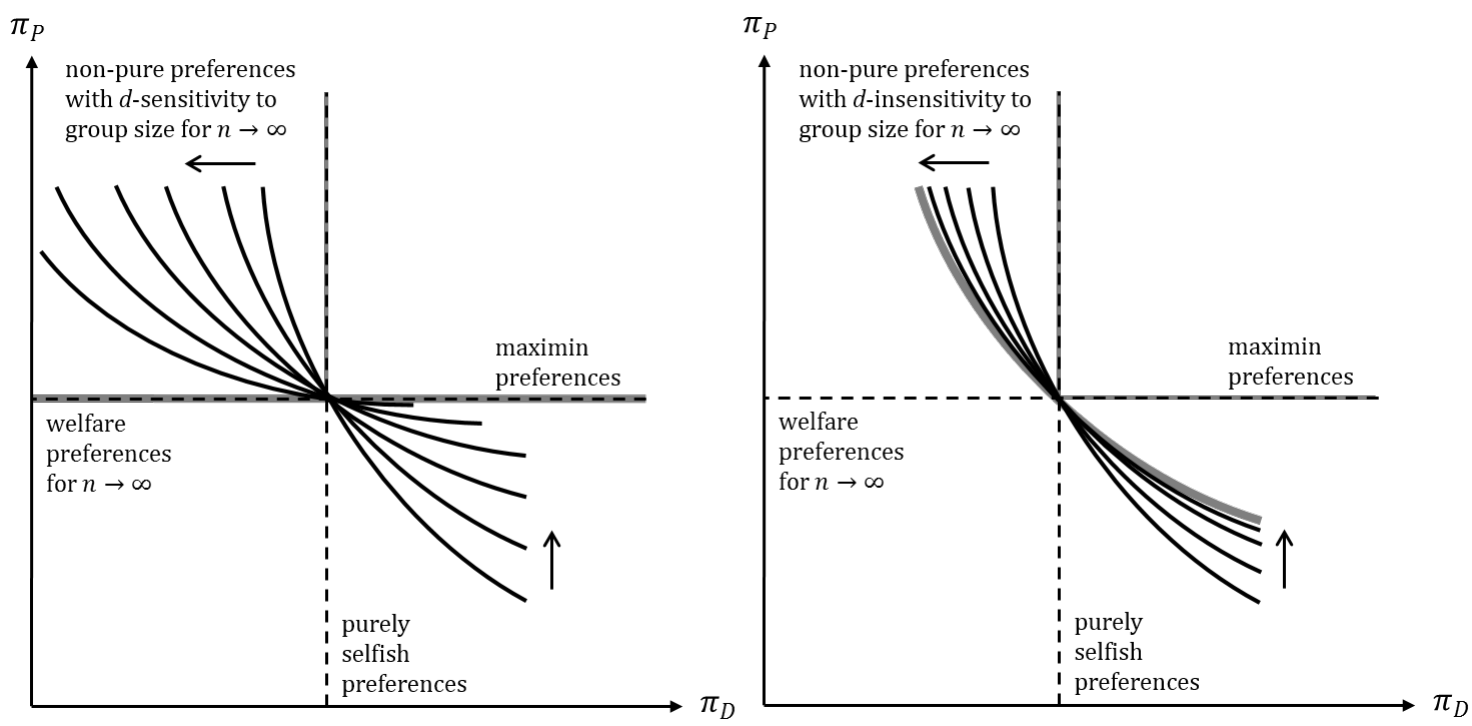

The dotted vertical line shows an indifference curve of purely selfish types. The dotted horizontal line shows an indifference curve of pure welfare types when $n \rightarrow \infty$. The thin grey curve shows an indifference curve of pure maximin types. The black curves show a sequence of indifference curves of non-pure types when $n \rightarrow \infty$ (with d-sensitivity to group size on the left, and with $d$-insensitivity to group size on the right). The bold grey curve represents their limit.

Similarly, the utility weight $h(n)$ defines the marginal rate of substitution between the receiver's and a payer's payoff. In a dispersed costs game with receiver benefit, an individual with utility function $U$ provides $x \in(0, \bar{x})$ if

$$
M R S_{R P}(x) \equiv \frac{1}{h(n)}\left(\frac{\pi_{P}(x)}{\pi_{R}(x)}\right)^{1-\rho}=\frac{c}{b} .
$$

She does not provide anything of the good if $M R S_{R P}(0) \leq c / b$, and the maximal amount if $M R S_{R P}(\bar{x}) \geq c / b$. The provision of the good decreases in $h(n)$. If $h(n)$ is sufficiently large, the decider will not provide the good. However, if she does not fully take into account the number of payers, i.e., $h(n)$ converges to some finite value for $n \rightarrow \infty$, she provides the good when the ratio $c / b$ is close enough to zero, regardless of how many payers there are. 
The following definition makes precise what it means than an individual either fully takes into account or does not fully take into account the number of payers.

Definition $1 A$ decider with non-pure preferences is called $d$-sensitive ( $r$-sensitive) to group size if $\lim _{n \rightarrow \infty} f(n)=\infty \quad\left(\lim _{\mathrm{n} \rightarrow \infty} \mathrm{h}(\mathrm{n})=\infty\right)$. Her provision of the good then converges to zero in each dispersed costs game with decider (receiver) benefit as the number of payers grows large. A decider is called d-insensitive ( $r$-insensitive) to group size if $\lim _{n \rightarrow \infty} f(n)<\infty \quad\left(\lim _{\mathrm{n} \rightarrow \infty} \mathrm{h}(\mathrm{n})<\infty\right)$. Then, there exist dispersed costs games with decider (receiver) benefit in which she provides at least $x>0$ units, regardless of the number of payers.

An individual may be both $d$-insensitive and $r$-sensitive to group size, or vice versa. Thus, our framework allows for deciders who make rather selfish choices in games in which they benefit from the good, but do not provide it in a dispersed costs game with receiver benefit if the number of payers is sufficiently large $:^{9}$ or deciders who stop taking from the payers once the costs of taking exceed the decider's benefits, while also redistributing resources from payers to the receiver, regardless of the number of payers.

We can now characterize behavior in dispersed costs games with decider and receiver benefit. In such games, there are two reasons to provide the good: to increase one's own payoff and to redistribute payoffs from the payers to the receiver. An individual whose preferences can be described by $U$ provides $x \in(0, \bar{x})$ if

$$
M R S_{D R P}(x) \equiv \frac{1}{f(n)}\left(\frac{\pi_{P}(x)}{\pi_{D}(x)}\right)^{1-\rho}+\frac{1}{h(n)}\left(\frac{\pi_{P}(x)}{\pi_{R}(x)}\right)^{1-\rho} \frac{b}{a}=\frac{c}{a} .
$$

She does not provide anything of the good if $M R S_{D R P}(0) \leq c / a$ and the maximal amount if $M R S_{D R P}(\bar{x}) \geq c / a$. Note that the ratio $b / a$ is positive. Hence, the decider provides a positive amount of the good, regardless of the number of payers, if she exhibits $d$ - or $r$-insensitivity to group size and the ratio $c / a$ is close enough to zero.

\subsection{Reversal in Behavior}

(In)sensitivity to group size generates an important behavioral phenomenon: depending on whether an individual is sensitive or insensitive to group size, we may observe decisions that at first sight seem contradictory. ${ }^{10}$ We call this "reversal in behavior."

\footnotetext{
${ }^{9}$ To see this, consider a dictator game and a dispersed costs game with decider benefit. Let $f(n)=\theta$ for all $n$ and $\theta>0$ be small enough so that the decider behaves selfishly in both games. If $g(n)=\theta / n$ for all $n \geq 1$ so that $h(n)=n$, then for any given dispersed costs game with receiver benefit, she provides nothing of the good if $n$ is sufficiently large; see the first-order condition in (5).

${ }^{10}$ Throughout this subsection, we assume that deciders have non-pure preferences.
} 
Reversal in generosity. Does generous or non-generous behavior in dictator games translate into similar behavior in situations with concentrated benefits and dispersed costs? The answer to this question depends on an individual's sensitivity to group size. A decider who is $d$-insensitive to group size can at the same time be willing to share in a dictator game, and take from many others in a dispersed costs game $(a, 0, c)$ if the ratio $c / a$ is close enough to zero. In contrast, a decider who is $d$-sensitive to group size and gives nothing in the dictator game will take nothing from the payers in the dispersed costs game - and thus behave generously — if the number of payers is sufficiently large. Both statements follow from the first-order conditions in (2) and (4).

Reversal in welfare and maximin concerns. Similarly, a decider may be concerned with welfare in dictator games: she gives a lot if the provision of the good increases the total payoff $(-a<b)$ and provides little otherwise $(-a>b)$. Another decider may be concerned with the equality of the receiver's and her own payoff, such that for given provision costs $a$ she gives more when the receiver's marginal return $b$ decreases. To what extent do these motives carry over to games with concentrated benefits and dispersed costs? If the decider with welfare concerns is $r$-insensitive to group size, she provides the good in a dispersed costs game $(0, b, c)$, regardless of the number of payers, if the ratio $c / b$ is sufficiently close to zero. Thus, when total costs are large but dispersed among many payers, she makes choices that actually reduce group welfare. In contrast, if the decider with equality concerns is $r$-sensitive to group size, then in any given dispersed costs game with receiver benefit she will not provide the good if there are too many payers. She then accepts the inequality between the receiver's and the payers' payoff in order not to damage group welfare. Both statements can be derived from the first-order conditions in (2) and (5).

\section{Experimental Design}

The goal of the experiment is to provide an empirical analysis of distributional preferences in situations with concentrated benefits and dispersed costs. In particular, we are interested in whether or not subjects take into account the number of individuals affected by their decisions.

Basic Setup. Subjects play a number of generalized dictator games. In each game, the decider's and the payers' endowment is $W_{D}=W_{P}=15$ tokens, while the receiver's endowment is $W_{R}=5$ tokens. The decider chooses the provision $x \in\{0,1, \ldots, 10\}$ of the good. We keep the framing constant across games. Table 1 displays the parameter values $(a, b, c)$ of all games as well as the actions that a pure preference type would choose: $x_{i}^{s}$ is the selfish action in game $i, x_{i}^{w}$ is the action that maximizes the group payoff (for treatments with eight or more payers), and $x_{i}^{m}$ is the action that maximizes the payoff 
of the least well-off individual of the group.

\section{[Insert Table 1 about here]}

The first three games are dictator games with varying values of the receiver's marginal benefit $b$; games 4 to 9 are dispersed costs games with decider benefit in which we both vary the decider's marginal benefit $a$ and the payers' marginal costs $c$; games 10 to 15 are dispersed costs games with receiver benefit in which we both vary the receiver's marginal benefit $b$ and the payers' marginal costs $c$; finally, games 16 to 18 are dispersed costs games with decider and receiver benefit, again with varying values of $b{ }^{11}$

Our treatment manipulation is the number of payers $n$; in each treatment, the number of payers is fixed. We consider five different treatments with $n$ equal to $1,4,8,16$, and 32. We call these treatments $P 1, P 4, P 8, P 16$ and $P 32$, respectively. In each treatment, subjects are paired up randomly into groups of size $n+2$. Each subject chooses the provision of the good $x$ in all 18 games. The sequence of games is the same in each treatment. After the experiment, we randomly pick one game for each group that is implemented. We also randomly select one subject from each group who takes on the role of the decider and one subject who takes on the role of the receiver. The other subjects of the group take on the role of payers. The decider's action in the chosen game then determines the payoffs of all group members. Hence, subjects' decisions can only affect their own payoff when they are chosen to be the decider, not when they are in the role of the receiver or of a payer. This is explicitly communicated to all subjects.

Subjects get no feedback about the actions of others except through their payment after the experiment. When making their decision, they receive detailed information about the potential consequences of their action on the decision screen: their own payoff, the receiver's payoff, the payoff of each payer, and the group payoff. Thus, the group payoff is as salient as any individual payoff 12

Control Treatments. Our experimental design implies that the probability with which a particular decision becomes effective varies between treatments. The realization probability equals $1 / 18 \times 1 /(n+2)$ in a treatment with $n$ payers. This variation may affect behavior, for example, through subjects' attention to the task or via demand effects (subjects in treatments with lower realization probability may behave more generously as their decisions are less likely to become effective). We therefore implement two control treatments, P16-17 and P32-9. These treatments differ in the number of payers (16 in P16-17 and 32 in P32-9), but the realization probability is exactly the same, because in

\footnotetext{
${ }^{11}$ Parameters in the dispersed costs games are chosen such that we also can analyze how the provision of the good changes when constant total costs are distributed over more and more payers. We examine this variation in the Online Appendix.

${ }^{12}$ See the Online Appendix for screenshots of the instructions and decision screens.
} 
P16-17 subjects play 17 games while in P32-9 subjects play only 9 games. Any difference between these two treatments cannot be attributed to the variation in the realization probability, but only to the variation in the number of payers. Moreover, by comparing behavior in the two treatments P32-9 and P32 we can check whether the realization probability matters for subjects' decisions, as the probability in the former treatment is twice as large as in the latter treatment.13

Experimental Procedures. The experiment was conducted online over the internet and administered by CentERdata, Tilburg University. On the first screens of the experiment, participants answered several survey questions on demographic variables. We then carefully explained the design using a number of numerical examples. Subjects could participate in the experiment only if they correctly answered two control questions. We recruited subjects through ORSEE (Greiner 2015) from the University of Munich. Our main motivation for conducting the experiment online was two-fold: First, many of the economic situations we have in mind (e.g., tax evasion) involve a high degree of anonymity between the decider and the group of payers. The online experiment, in which subjects decide without the other parties being physically present, mimics this important feature. Second, by running the experiment over the internet we also kept the degree of anonymity constant across treatments. This would not be possible in a classic lab environment, where the degree of anonymity may vary with the number of subjects who are present. To check whether our choice of an online experiment influences behavior, we recruited additional subjects who participated in our study in an experimental lab. We do not find any behavioral differences and therefore pool the data from both sources ${ }^{14}$ All data was obtained in anonymized form, which was made clear to the participants in the invitation and also on the first screen of the experiment. In total, 502 participants completed the experiment over the internet, and 79 participants in the experimental lab; 75 participants were allocated to treatment $\mathrm{P} 1,78$ to treatment $\mathrm{P} 4,69$ to treatment $\mathrm{P} 8$, 71 to treatment P16, 99 to treatment P32, 89 to treatment P16-17, and 100 to treatment P32-9. ${ }^{15}$ A participant's final payoff of $\pi$ tokens was converted into $0.65 \pi$ Euros. Average earnings in the experiment (which include a 4 EUR show-up fee) were 11.80 Euros.

\footnotetext{
${ }^{13}$ In treatment P16-17 subjects play all games except game 13. In treatment P32-9, subjects play games 1 to 6 and games 10 to 12 .

${ }^{14}$ See the Online Appendix for details on procedures and results.

${ }^{15}$ We ensured the necessary number of $n+2$ players in each treatment by filling up incomplete groups with participants who did not answer the control questions correctly (they were assigned the roles of receivers or payers).
} 


\section{$5 \quad$ Experimental Results}

In the results section, we proceed as follows. We first analyze behavior in the dictator games to see whether behavior in our experiment is consistent with previous results in the literature (Section 5.1). Then we consider the dispersed costs games. We start by investigating average behavior in dispersed costs games with decider and receiver benefit (Section 5.2). These games are at the core of our interest in view of economic applications. Subsequently, we go into details by analyzing average as well as heterogeneity of individual behavior in dispersed costs games with decider benefit (Section 5.3), and in dispersed costs games with receiver benefit (Section 5.4). Finally, we examine the extent of reversals in behavior (Section 5.5) ${ }^{16}$

\subsection{Behavior in Dictator Games}

The data from the dictator games allow us to check whether subjects' behavior is comparable to that in previous studies on dictator game giving. This is important in order to rule out that our results are caused by subject pool effects. Note that the only difference between the dictator games played in the different treatments is the probability with which a subject's decision is implemented. The variation in this probability could in principle affect behavior, either via subjects' attention to the decision task or via demand effects. In the Online Appendix, we show that the realization probability has no significant effect on subjects' behavior. On average, subjects provide the same amount in the dictator games, regardless of whether there is only one payer (so that the realization probability equals $1 / 54$ ) or 32 payers (so that the realization probability is $1 / 612$ ). We also find no significant differences in behavior between the treatments P32 and P32-9 or between P16-17 and P32-9 for any other type of game. In the following, we therefore pool the data from all treatments.

In dictator game $1(a=-1.0, b=1.5)$, the average provision of the good is 2.19 units; in dictator game $2(a=-1.0, b=1.0)$, it is 2.05 units; and in dictator game 3 $(a=-1.0, b=0.5)$, it is 1.82 units. The share of subjects who provide zero in all dictator games is 35.1 percent. These numbers are very close to previous results in the literature. In his meta-study, Engel (2011) reports that the share of participants in dictator games who do not give anything to the receiver is 36.1 percent. In Andreoni and Miller (2002), average giving is equal to 16.9 to 24.3 percent (in our data 20.5 percent) when the price of giving is 1; and 20.7 to 21.2 percent (in our data 18.2 percent) when the price of giving is 2. Moreover, we find the gender effect from Andreoni and Vesterlund (2001). Men

\footnotetext{
${ }^{16}$ Table 5 in the Appendix summarizes subjects' behavior in all treatments and games. Moreover, it contains details on the subgroup analysis we employ in this section.
} 
provide more of the good than women if the provision of the good increases the group payoff, and less if it decreases the group payoff (see the Online Appendix). We conclude that the results from our dictator games are in line with those in previous studies.

\subsection{Behavior in Dispersed Costs Games with Decider and Re- ceiver Benefit}

In the dispersed costs games 16 to 18, providing the good benefits the decider and the receiver, but creates costs for the payers. The more payers there are, the larger are the total costs of provision. With four or more payers, the group payoff is maximal when nothing of the good is provided. Figure 2 displays the average provision in these games for all treatments. The main observation is startling. While subjects on average provide eight units if there is only one payer, they provide about six units on average if the number of payers is larger than one, independent of whether this number is $4,8,16$, or 32. In all three games, the average provision is significantly larger in treatment P1 than in $\mathrm{P} 4(p-$ value $<0.001)$, but there is no significant difference between treatments P4 to P32 $(p-$ value $>0.591) .17$ This behavior has detrimental consequences for the group payoff. For example, in game 18 of treatment P32, the average provision implies an increase of 5.63 tokens in the decider's payoff and an increase of 2.81 tokens in the receiver's payoff, at a total cost of 180.04 tokens for the group of payers.

Figure 2: Provision in dispersed costs games with decider and receiver benefit

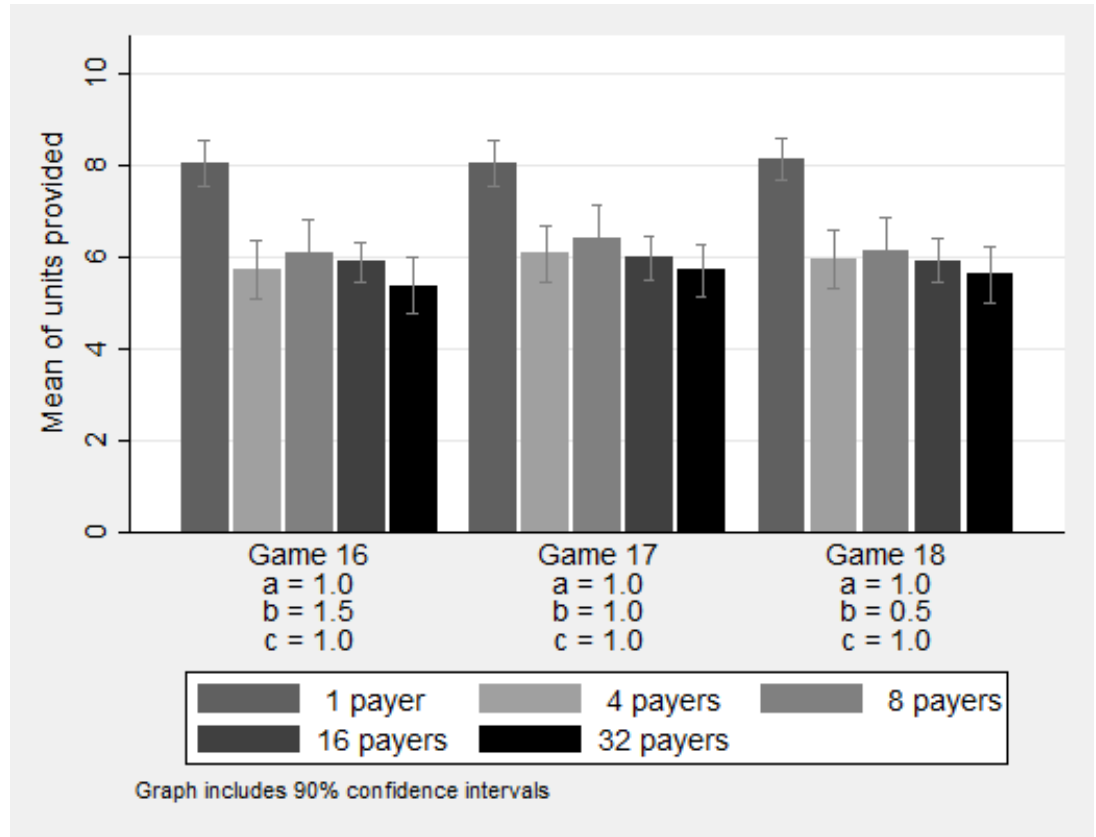

${ }^{17}$ Throughout the paper, $p$ - values come from linear regressions. 
Result 1 Subjects provide substantial amounts in dispersed costs games with decider and receiver benefit. While the average provision is significantly lower when the number of payers increases from 1 to 4 , there is no significant difference when the number of payers increases from 4 to 8,16 , or 32.

According to our model, there are three potential explanations for this result: first, pure selfish types provide the good to maximize their own payoff; second, pure maximin types provide the good to equalize the receiver's and a payer's payoff; finally, non-pure types, who are insensitive to group size, care for the payoff of all parties but do not fully take into account the number of payers. For them, some provision of the good can be optimal. We now examine the relevance of each explanation by analyzing the size and the behavior of these subgroups using data from the remaining dispersed costs games.

\subsection{Behavior in Dispersed Costs Games with Decider Benefit}

In the dispersed costs games 4 to 9, providing the good entails benefits for the decider and costs for all payers. There is no additional redistribution motive towards the receiver. Figure 3 shows how the average provision of the good varies across the six games and across treatments. Overall, the provision of the good slightly decreases in the number of payers, but the changes are small relative to the increase in provision costs. The implied damage for the group payoff is again substantial. For example, in game 6 of treatment P32, the average provision increases the decider's payoff by 2.10 tokens at a cost of 134.08 tokens for the payers. Despite this, subjects reveal that they do "care" for welfare: their provision of the good significantly increases in their own marginal payoff $a$, and decreases in a payer's marginal cost $c$ (see specification 1 and 2 of Table 2 ).

Since each subject is confronted with only one group size, we cannot determine directly whether a particular individual is $d$-insensitive to group size or not. Nevertheless, the data allow us to provide a conservative estimate of the share of these subjects. If all subjects with non-pure preferences were $d$-sensitive to group size, we should observe that their provision of the good converges to zero as the number of payers grows large. However, if a subject with non-pure preferences is $d$-insensitive to group size, her provision may converge to a strictly positive value.

We use this to analyze the data. First, we identify and exclude all subjects who act like pure selfish or pure maximin types in the dictator games. We call them "selfish types" and "maximin types", respectively.18 Overall, 35.1 percent of our subjects are selfish types and 8.0 percent are maximin types 19 Next, from all remaining subjects we

\footnotetext{
${ }^{18}$ In the Online Appendix, we do the same analysis allowing for errors of maximin types.

${ }^{19}$ See Table 5 in the Appendix for the respective shares in each treatment.
} 
Figure 3: Provision in dispersed costs games with decider benefit

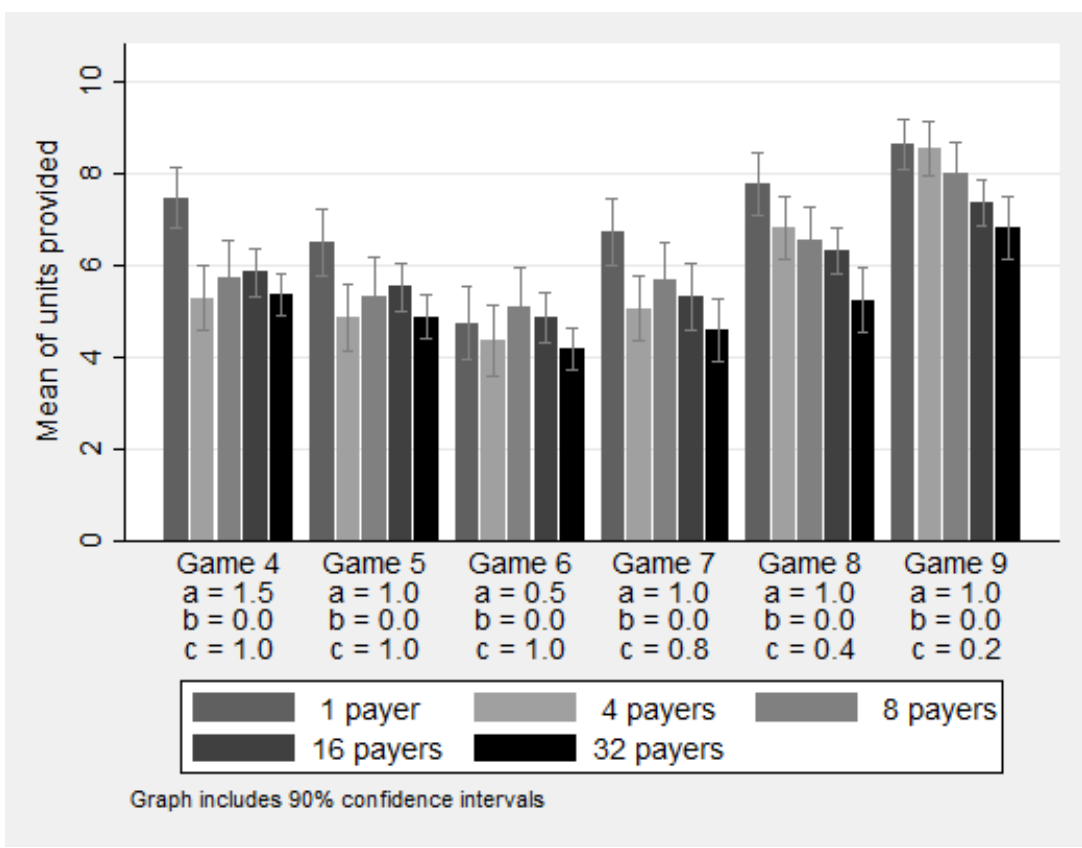

Figure 4: Average provision of different types (Games 4 to 6 )

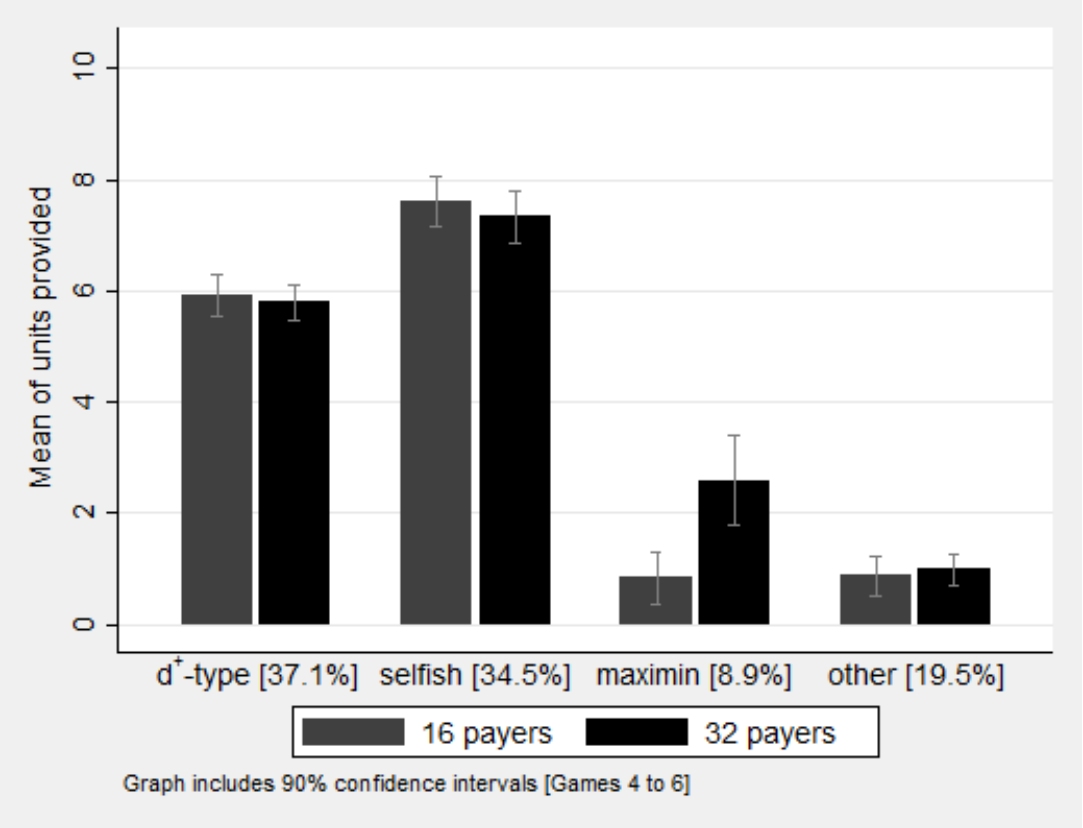


consider those who provide positive amounts in each of the dispersed costs games 4 to 6.20 We call them " $d^{+}$-types." Then we analyze to what extent the average provision and the share of these subjects varies across treatments. In particular, we are interested in their behavior in the limit when the number of payers becomes large. If both values remain constant across the treatments P16 and P32 (which is indeed what we find), their share in these treatments is a good estimate for the fraction of subjects who are $d$-insensitive to group size 21

The $d^{+}$-types provide substantial amounts of the good in the dispersed costs games with decider benefit, see Figure 4. A regression analysis shows that their behavior in these games does not vary significantly between the treatments P8, P16 and P32 (see specifications 4 and 5 of Table 2). On average these types take the welfare of all parties into account: their provision increases in their own marginal payoff $a$, and decreases in a payer's marginal cost $c$. Their share does not vary significantly between the treatments P8 to P32 (see specification 3 of Table 2), and their shares are rather close to each other in P16 and P32 (38.8 and 35.7 percent, respectively; $p-$ value $=0.542$ ). Their average share in these treatments is 37.1 percent, which constitutes our conservative estimate of the share of subjects who exhibit $d$-insensitivity to group size.

\section{[Insert Table 2 about here]}

To see which types create the huge welfare losses, we compare in Figure 4 the behavior of the different subgroups in the dispersed costs games 4 to 6 of the treatments P16 and P32. The subjects we classified as $d$-insensitive to group size provide on average 5.85 units in these games. Unsurprisingly, selfish types provide the most, on average 7.46 units. We see a slight, mostly insignificant downward trend in their provision of the good as the number of payers increases (see specification 6 of Table 2). Maximin types provide on average only 1.84 units and subjects who do not belong to any of these groups provide on average only 0.95 units. In sum, we find that both selfishness and $d$-insensitivity to group size contribute equally to the inefficient provision of the good in dispersed costs games with decider benefit when there are many payers.

Result 2 Subjects provide substantial amounts in dispersed costs games with decider benefit. The average provision decreases only slightly in the numbers of payers. This

\footnotetext{
${ }^{20}$ We use these games as they were played by all subjects in both the main and the control treatments.

${ }^{21}$ We consider this estimate to be a conservative lower bound. Subjects who are classified as selfish or maximin types might also have non-pure preferences and exhibit insensitivity to group size. Moreover, subjects who provide zero in the dispersed costs games 4 to 6 might provide positive amounts regardless of the number of payers when the costs per payer are smaller than the values chosen in our experiment. In the Online Appendix, we therefore consider a stricter classification of selfish and maximin types and thus provide a less conservative lower bound.
} 
result is driven by subjects who act like purely selfish types in the dictator games (34.5 percent of our sample) and by subjects who are d-insensitive to group size (37.1 percent of our sample).

\subsection{Behavior in Dispersed Costs Games with Receiver Benefit}

In the dispersed costs games 10 to 15, the provision of the good redistributes payoffs from the payers to the receiver but does not benefit the decider. Thus, it is costless for subjects to make choices that maximize group welfare. Figure 5 shows the average provision of the good in these games for all treatments. Subjects' behavior appears even less responsive to the number of payers compared to what we found in the dispersed costs games with decider benefit. The provision of the good remains largely constant, regardless of whether there are 4, 8, 16 or 32 payers. This again implies substantial welfare losses. For example, in game 12 of treatment P32, the average decision is to provide 3.35 units, which increases the receivers' payoff by 1.68 tokens but reduces the payers' total payoff by 107.20 tokens. Nevertheless, subjects on average do take into account the costs per payer: the provision of the good significantly decreases in the marginal costs $c$ (see specification 1 and 2 of Table 3 ).

The data allow us to provide a conservative estimate of the share of subjects who are $r$-insensitive to group size. As before, we exclude all subjects who act like pure selfish or pure maximin types in the dictator games. From the remaining subjects we consider those who provide positive amounts in each of the dispersed costs games 10 to 12 and call them " $r^{+}$-types." Then we examine to what extent their share and behavior varies across treatments.

The $r^{+}$-types provide substantial amounts of the good, regardless of the number of payers, see Figure 6. Their average provision hardly varies between the treatments P8, P16 and P32 (see specifications 4 and 5 of Table 3). The average reaction to the receiver's marginal payoff $b$ is significantly negative $(p-$ value $<0.1)$, which indicates that on average they care more about equality than welfare in the dispersed costs games with receiver benefit. However, only 1.4 percent of them choose the maximin action in at least two of these games and none chooses the maximin action in more than two games. Their share does not systematically vary in the number of payers (see specification 3 of Table 3). The only significant difference is in P8, but the mean share of $r^{+}$-types in P8 is lower, not higher than in P32. In particular, their shares in the treatments P16 and P32 are not significantly different from each other (33.8 and 40.7 percent, respectively; $p-$ value $=0.168$ ); the average share in these treatments is 37.6 percent, which constitutes our estimate of the share of subjects who exhibit $r$-insensitivity to group size. There is a positive correlation between the probability of being classified as 
Figure 5: Provision in dispersed costs games with receiver benefit

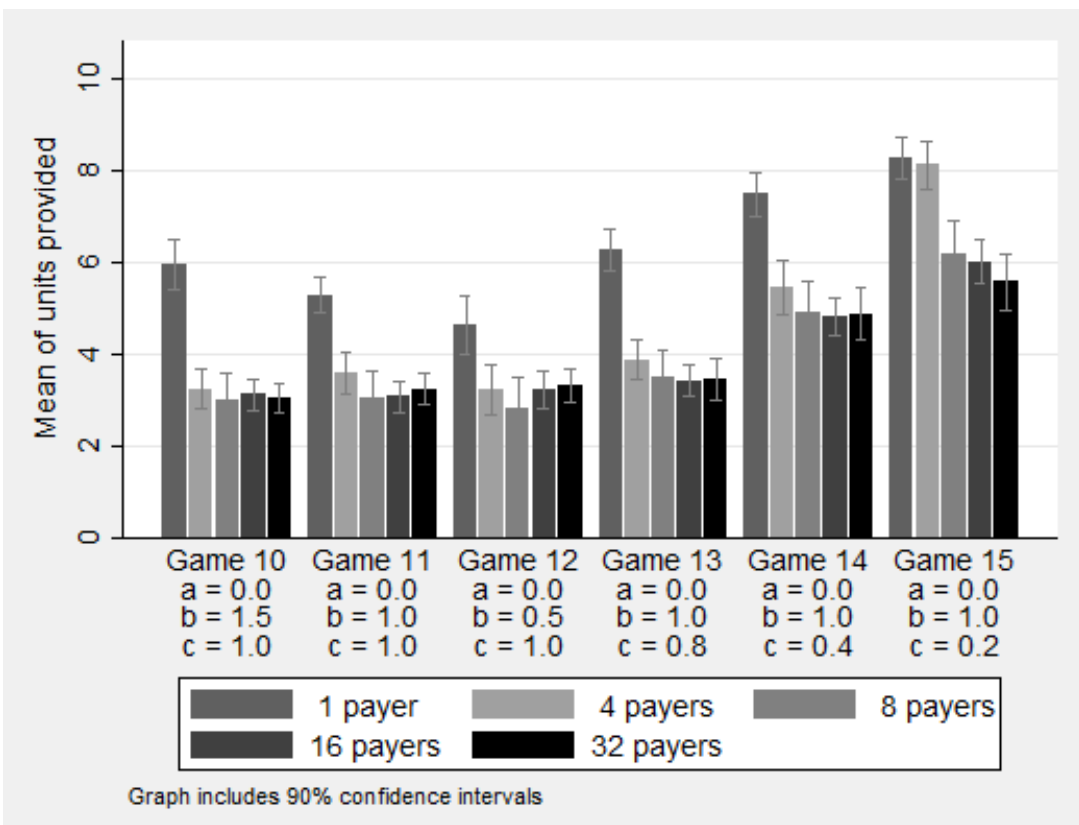

Figure 6: Average provision of different types (Games 10 to 12)

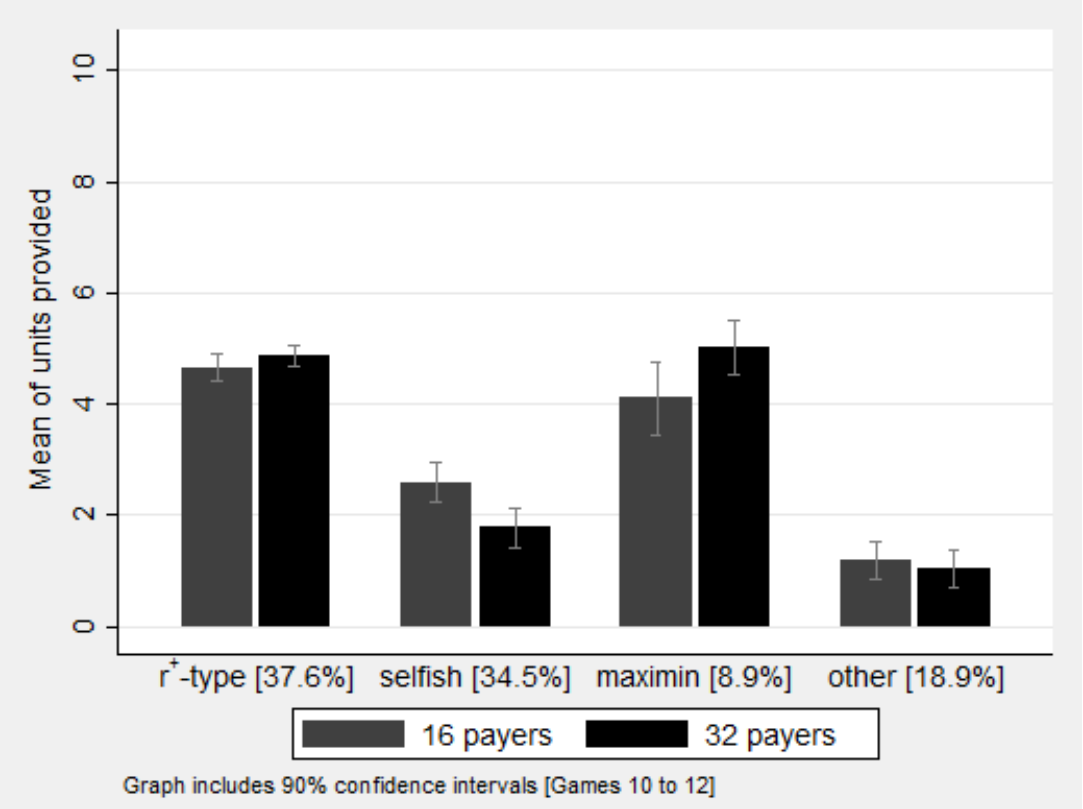


$d$ - and $r$-insensitive to group size. Pooling the data from the P16 and P32 treatments, the estimated correlation is 0.63 .

\section{[Insert Table 3 about here]}

Figure 6 compares the behavior of the different subgroups in the dispersed costs games 10 to 12 when there are 16 or 32 payers. While those subjects that we classified as $r$-insensitive to group size provide on average 4.78 units, selfish types on average provide only 2.19 units. Moreover, selfish types significantly lower the provision of the good as the number of payers increases (see specification 6 of Table 3). Maximin types provide on average 4.64 units, and consistent with their behavioral motivation, their provision does not vary significantly across treatments (see specification 7 of Table 3 ). Subjects who belong to neither of these groups provide on average 1.11 units. As the share of maximin types is small, the main reason for the inefficient provision of the good in these games are thus subjects who are $r$-insensitive to group size.

Result 3 Subjects provide substantial amounts in dispersed costs games with receiver benefit. The average provision remains constant when there are 4, 8, 16 or 32 payers. This result is driven by subjects who are $r$-insensitive to group size (37.6 percent of our sample). The estimated correlation between being $d$-and $r$-insensitivity to group size equals 0.63 .

\subsection{Results on Reversals in Behavior}

So far, our analysis shows that $d$ - and $r$-insensitivity to group size is the main explanation (together with pure selfishness) for the observed behavior and inefficiency in our experiment. We now analyze whether the observed (in)sensitivity also leads to reversals in behavior as discussed in Section 3.3 .

We focus on two games where costs per payer are small but total costs are large: game $9(a=1.0, b=0.0, c=0.2)$ and game $15(a=0.0, b=1.0, c=0.2)$ in treatment P32. In both games, one additional token for the decider/receiver creates costs of 6.4 tokens for the group of payers. In game 9, generous behavior means to provide little or nothing of the good, while selfish behavior means to provide the maximal amount. In game 15, welfare maximizing behavior implies to provide nothing, while the action that maximizes the welfare of the least well-off individual is to provide nine units of the good. To identify reversals in behavior, we first create behavioral measures for generosity, welfare, and maximin concerns in the three dictator games and rank subjects according to these measures. We then compare the behavior of subject groups from the extremes of the distribution. A subject's generosity in the dictator games is defined as 
gen $=\frac{1}{3} \sum_{i=1}^{3} x_{i}^{2}$. With regard to welfare and maximin concerns, we consider the squared distance to the actions of the pure preference types, ${ }^{22}$ i.e., $w e l=\frac{1}{3} \sum_{i=1}^{3}\left(x_{i}^{w}-x_{i}\right)^{2}$ and $\max =\frac{1}{3} \sum_{i=1}^{3}\left(x_{i}^{m}-x_{i}\right)^{2}$.

\section{[Insert Table 4 about here]}

Reversal in generosity. Consider game 9. In the top left panel of Table 4 we compare behavior of the least generous subjects in the dictator games (those who give zero; 29.3 percent in P32) with that of the remaining subjects. As can be seen, only very few of the selfish subjects ( 7 percent) provide nothing of the good in game 9 , compared to 20 percent of the non-selfish subjects. At the same time, 86 percent choose the maximum amount, compared to 43 percent of the others. Thus, the behavior of selfish subjects seems very consistent across games. The situation looks different when we consider the most generous quarter of subjects in the dictator games $($ gen $>20.33)$ and compare their behavior with that of the remaining population, see the top right panel of Table 4 . While on average the top generous quarter provide less than the bottom 75 percent (3.93 versus 8.04 units, $p-$ value $<0.001$ ) and also more frequently provide zero (34 percent versus 9 percent, $p$ - value $<0.001)$, 24 percent of them do provide the maximum amount. These subjects give very generously in the dictator games and at the same time take selfishly from many others when the costs per payer are small.

Reversal in welfare and maximin concerns. We first compare the behavior of the quarter whose actions are closest to those of the pure welfare type $($ wel $<26.5)$ with that of the remaining subjects, see the bottom panel of Table 4. On average, the provision of the good does not differ between these groups (5.52 versus 5.62 units, $p$-value $=0.455)$ and similar shares provide 9 or 10 units of the good (around 20 percent). Thus, a considerable share of subjects who behave as if they care for welfare in dictator games, also redistribute payoffs when costs are dispersed, thereby creating a substantial loss in welfare. Looking at maximin concerns, we find little evidence for reversal in behavior. Subjects in the top quarter with respect to maximin concerns $(\max <2.50)$ provide significantly more in game 15 than the rest $(7.66$ versus 4.72 units, $p$-value $<0.001$ ), and not a single one of them chooses to provide zero. Note that similar to selfish subjects in game 9, a potential reversal of behavior of maximin types in this game would be caused by group size sensitivity, which we hardly see in our data. Instead, most reversals we do observe (generosity and welfare) are based on group size insensitivity.

\footnotetext{
${ }^{22}$ Note that the two latter measures capture the degree to which these concerns do not play a role for subjects' behavior in the dictator games.
} 


\section{Discussion}

How can we explain that a substantial fraction of subjects in our experiment reveal to be insensitive to group size? In this section, we discuss cognitive, psychological, and moral arguments for the existence of such preferences.

Attention. One reason why subjects may exhibit insensitivity to group size is that they simply overlook the actual number of payers. To rule this out, we made the number of payers very salient to subjects in the experimental instructions, both verbally and graphically (see the Online Appendix for screenshots). Moreover, we explicitly state the number $n$ of payers on each decision screen. Thus, group size was as transparent to subjects as any other payoff-relevant detail of the experiment. In addition, note that we do observe a reaction to group size when we increase the number of payers from one to four in most dispersed costs games. One therefore cannot explain insensitivity to group size by subjects accidentally ignoring $n$.

Cognitive effort and ability. An alternative explanation could be that subjects did not properly understand the payoff consequences of their actions. Again, to minimize this concern the experiment was explained in very simple terms. Subjects could only take part in the experiment if they had correctly answered the control questions on payoff consequences. Still, one might conjecture that some subjects exert little cognitive effort on grasping all the relevant payoff details and therefore ignore the number of payers. To analyze the role of cognition on decisions, we proxy cognitive effort by decisionmaking time (the total time spent on the experiment). We find that subjects with above-median decision-making time behave very similarly to those with below-median decision-making time, and that the shares of insensitive types in these subgroups are also very comparable.23 In particular, we do not find that most insensitive types take belowmedian time to make their decisions. Hence, we do not think that a lack of cognitive effort drives our results. Next, we proxy cognitive ability by subjects' high school grade point average (which we recorded in the survey before the experiment). We find no significant behavioral differences between subjects with above- and below-median grades. Thus, there is no indication that our results are driven by an imperfect understanding of the experimental rules. However, as we discuss next, there are psychological as well as moral arguments for why individuals may be insensitive to group size.

A psychological perspective. We can only speculate at this point about concrete psychological processes behind insensitivity to group size. One potential mechanism is the ability to put oneself in someone else's position. Already in his Theory of Moral Sentiments, Adam Smith proposed that humans have a strong tendency and ability to empathize with others, arguably one of the main factors why humans act pro-socially.

\footnotetext{
${ }^{23}$ See the Online Appendix for details.
} 
Yet, it seems difficult to put oneself in the position of a whole group of people. The more natural thing would be to take the position of a representative member of the group, which may induce decision makers to ignore the size of an affected group. As mentioned in Section 2, also Kahneman et al. (1999) argue that the phenomenon of extension neglect, observed in the contingent valuation literature, is due to what they describe as "valuation by prototype": An individual's attitudes towards a group are primarily determined by her attitudes towards a representative member of this group, implying that group size receives only little weight in the valuation 24

There is work in psychology demonstrating that forming impressions of individuals and groups are indeed two distinct cognitive processes (Hamilton and Sherman 1996). Susskind et al. (1999) provide empirical evidence for this hypothesis. In their study, subjects are asked to read a list of statements describing behaviors performed either by an individual or by a group. Subjects then rate the coherence of the described patterns and the characteristics of the target (e.g., sociability, intelligence). The results show that the single individual is viewed as a psychologically more coherent unit than the group. Subjects who had to rate the individual also made more extreme ratings, made their ratings more quickly, and were more confident about their judgments. This suggests that different cognitive processes underly our perception of and behavioral tendencies towards individuals and groups.

A moral justification. Can preferences with insensitivity to group size be morally justified, despite their potentially negative consequences for overall welfare? There is a significant literature on distributive justice that deals with this problem (e.g., Fleurbaey and Tundgodden 2010, Voorhoeve 2014, Cowell et al. 2015). Specifically, it attempts to answer the following question: Should the number $n$ matter, if the welfare of one poor individual is traded-off against the welfare of $n$ rich individuals?

The philosopher Alex Voorhoeve offers an intriguing argument under what circumstances the answer may be "no" from a moral point of view. Consider a situation like the dispersed costs games with receiver benefit. According to Voorhoeve (2014), both the receiver and every payer have a "claim", i.e., a moral entitlement, to be made better-off (or not worse-off) by the decider. The decider now places herself in the situation of each individual who has a claim (receiver and $n$ payers) and weighs competing claims against each other. In essence, she compares the claims of the receiver and a single payer. A claim is "strong" if someone benefits a lot from being helped and/or has a low initial endowment. If the receiver's claim is sufficiently strong relative to a payer's claim, it is morally justifiable not to take the number $n$ of payers into account. To illustrate,

\footnotetext{
${ }^{24}$ Kahneman et al. (1999) also suggest that valuation by prototype generalizes a number of well-known judgment biases, i.e., judgment by representativeness (the "Tom W problem"), judgment by similarity to stereotypes, and duration neglect.
} 
suppose that the receiver is really poor relative to the payers, and the receiver's benefit from the provision of the good is large relative to the costs per payer. One then can argue that a single payer should allow for some provision of the good to improve the receiver's condition. She alone does not lose much and the receiver is much better-off. Since the same argument applies to each of the $n$ payers, the number $n$ should not matter for the decider's action. In this sense, group size insensitivity (at least, $r$-insensitivity) can be morally justified.

\section{Implications}

The theoretical and empirical findings in our paper have important implications for economic policy. We discuss four different domains where group size insensitivity can explain a number of behavioral patterns: the approval of public policies with large, dispersed costs, ethical behavior, medical decision making, and charitable giving. In each domain, alternative interpretations may exist, but insensitivity to group size provides a unified explanation for all phenomena.

Approval of public policies with large but dispersed costs. Several economic or political decisions create benefits for a small group of individuals at relatively large costs for society. For instance, labor union strikes are sometimes not only very costly for employers, but also for the rest of the society when the industry that sees strike action has a large set of customers or is important for other sectors of the economy. Nevertheless, people often do not judge such actions as inappropriate or unethical.

A prominent example is the German labor union for locomotive drivers (GDL), which went on strikes nationwide eight times between 2007 and 2015, sometimes for a number of subsequent days. The GDL represents around 34.000 employees, which equals 0.08 percent of all employees in Germany. A strike by the GDL severely impairs the carriage of passengers and the transportation of goods. It is estimated that a day on strike produces economic losses of around 100 million Euros, which corresponds to 1.2 percent of Germany's daily GDP. Nevertheless, there is surprisingly little public resistance against these strikes and a significant fraction of the population even regard them as justified. Surveys conducted in 2011 and 2015 reveal that 73 and 46 percent of respondents, respectively, approve of the GDL's strikes. ${ }^{25}$ One explanation for this observation is that insensitivity to group size causes people to underweight large costs that are imposed on society relative to the (potential) gains of a small group that has some moral entitlement

\footnotetext{
${ }^{25}$ For the economic costs on strikes, see the estimates for the strike of 2015 on statista.com (accessed on 09/15/2015), or for earlier strikes in Kemfert and Kooths (2008). For the approval of these strikes, see statista.com on the survey question (in German) "Do you approve of the locomotive drivers' strike?" (accessed on $09 / 15 / 2015$ ).
} 
to these gains.

This implication advances an important political science debate. In his famous work The Logic of Collective Action, Mancur Olson (1965) argues that small groups (such as lobbies) are more effective in managing the free-rider problem and thus more likely to further their interests in the political process. These interests often are at odds with societal welfare so that a small group may exploit the majority of citizens. We add to this idea that decision makers who are insensitive to group size may even support this mechanism: Politicians who otherwise act pro-socially may evaluate policies with concentrated benefits and dispersed costs too positively (so that only a small degree of lobbying is required). Voters may show too little resistance against a minority's political behavior, or may even tolerate it, when its costs to society are sufficiently dispersed.

Moral ambiguity. Non-pure social preferences with insensitivity to group size imply that both pro- and anti-social decisions can be optimal at the same time. Take, for example, donations to a needy receiver and tax evasion. The decider maximizes utility from both activities, possibly at different points in time and with a different mindset, but with the same distributional preferences. If the decider is altruistic towards the receiver, she donates a positive amount. If additionally she is $d$-insensitive to group size and the number of affected citizens is large, she also evades taxes. Thus, optimal levels of donations and hidden income can be strictly positive at the same time.

In the experiment, such behavior was not infrequent: 24 percent of the most generous quarter of subjects in the dictator games also take the maximal amount from payers when the costs of taking are dispersed. Empirically, we observe that both charity donations and dishonest behaviors such as insurance fraud and tax evasion - criminal activities where there are many victims who suffer small losses - are substantial. In 2009, total philanthropy in the United States amounted to 300 billion USD (227 billion USD from individuals). At the same time, the magnitude of fraud in the US property and casualty insurance industry is estimated to be around 32 billion USD every year (around 10 percent of claims) ${ }^{26}$ and the estimated difference between tax liability and paid taxes exceeds 300 billion USD ${ }^{27}$ Naturally, there exist no data about how many individuals are engaged in philanthropy and fraud at the same time. However, the pervasiveness of both phenomena and evidence of dishonest behavior even among respected members of society (e.g., Mazar et al. 2008) suggests that this number is sizable.

Concerns for the patient, not for insurance holders. The idea that physicians have concerns for the patient is well-established in the health economics literature (e.g., McGuire 2000). Several papers assume that physicians' utility function is given by

\footnotetext{
${ }^{26}$ See iii.org/issue-update/insurance-fraud (accessed on 09/15/2015).

${ }^{27}$ Estimate by the IRS for 2006 at irs.gov (accessed on 09/15/2015).
} 
$U\left(\pi_{D}, \pi_{R}\right)$, where $\pi_{D}$ is their own income and $\pi_{R}$ the patient's welfare. In contrast, there are no concerns for the welfare of insurance payers. Indeed, the empirical evidence on physician choices suggests that patients with better insurance coverage are more likely to receive high-cost treatments compared to those with less extensive coverage ${ }^{28}$

Social preferences with insensitivity to group size qualify this assumption. A decider with such preferences takes the welfare of all parties into account, but gives little weight to costs that are dispersed among many individuals. Consequently, insurance protection changes physicians' behavior. Consider a physician who decides whether a treatment should take place $(x=1)$ or not $(x=0)$. The treatment benefits the patient, but it is not essential for her recovery. The patient fully relies on the physician's recommendations. The physician's remuneration is ax, the patient's net benefit $b x$, and the total costs are $C x$, where $a, b, C>0$. Either the patient or her insurance company pays for the costs of treatment. Suppose that the treatment is inefficient in the sense that $a+b<<C$.

Assume first that the physician is motivated only by economic self-interest. She will then choose the treatment, regardless of whether the patient or an insurance company pays for it. Insurance protection creates no additional costs. Next, assume that the physician exhibits non-pure social preferences with insensitivity to group size. She will then not choose the treatment in case of no insurance protection if she sufficiently cares about the patient's welfare. However, she will choose the treatment if the costs are dispersed among sufficiently many customers of the insurance company. Insurance protection then decreases welfare by $C-a-b>>0 .{ }^{29}$

Congestible altruism. Non-pure social preferences with insensitivity to group size imply that charity donations to a single individual can exceed those to a large group. If a donation $x$ is distributed among $n$ individuals and $n$ is large, it is worth less to

${ }^{28}$ Mort et al. (1996) elicit hypothetical treatment decisions in a nationally representative survey of physicians. They randomly vary patient attributes to identify the influence of insurance status on treatment decisions. Physicians recommended medical services more frequently to insured patients than to uninsured ones. McKinlay et al. (1996) use a videotape study to analyze the influence of several socio-economic variables on physicians' decisions. In the subsample of old patients, insured patients were more likely to get a cardiac diagnosis for chest pain, which creates greater subsequent costs than the gastrointestinal or psychogenic alternatives. Movsas et al. (2012) analyze U.S. administrative data and show that Caesarian sections are more likely to be performed on privately insured mothers than on those without insurance. Rischatsch et al. (2013) find that brand-name drugs are less often substituted by generic drugs for patients with lower co-payments for branded drugs in Switzerland. On a more general level, Chandra and Skinner (2012) demonstrate that the availability of treatments that are on average ineffective create rapid growth in health care costs when patients are fully insured.

${ }^{29}$ These costs of insurance are different from those created by moral hazard. Moral hazard causes costs because the insurance holder (or the physician) exploits a situation of asymmetric information. Our costs of insurance occur because one party (the physician) weighs differently the welfare of a single individual (the patient) and the welfare of a party that consists of many individuals (insurance holders). 
the decider than a donation of $x$ to a single individual. Hence, to maximize a giver's propensity to donate it is important for charity organizations to highlight the fate of one specific recipient that depends on the giver's benevolence. In fact, many organizations advertise their request by promoting the stories of individual recipients.

There is some evidence that altruism depends on the number of recipients. Kogut and Ritov (2005) find that contributions for a single victim exceed those for a group of eight victims when these two situations are judged separately. Andreoni (2007) studies how donations depend on the number of receivers. He finds partial congestion: when the number of receivers doubles (and each receiver gets a constant amount per unit provided), the value of a donation to the giver increases by a factor less than two. This means that if we keep constant the marginal effect of a donation to a single recipient, donations increase in $n$, but at a decreasing rate. In our case, $d$-insensitivity to group size implies that donations do not at all increase in $n$, i.e., there is full congestion.

\section{Conclusion}

We study distributional preferences in games with concentrated benefits and dispersed costs. In these games, it does not only matter to what extent the decider cares about the welfare of others, but also whether she takes into account the number of individuals affected by her decision. We formally define two ways in which deciders with non-pure distributional preferences may ignore this number. If a decider is $d$-insensitive to group size, she redistributes resources from payers to herself, regardless of the number of payers, as soon as the costs per payer are sufficiently small relative to her benefits. If she is $r$ insensitive to group size, she redistributes resources from payers to a needy receiver, regardless of the number of payers, when the costs per payer are small enough relative to the receiver's benefits.

Our experimental data reveal that a significant fraction of subjects exhibits insensitivity to group size: at least 37.1 percent are $d$-insensitive to group size, and at least 37.6 percent are $r$-insensitive to group size. These subjects take the welfare of all parties into account, but large groups of payers just receive the same weight as small groups. Consequently, the degree of redistribution we observe in our dispersed costs games is substantial even if the costs of redistribution by far exceeded its benefits. The combination of non-pure social preferences and group size insensitivity can explain a number of empirical patterns such as the approval of public policies with small benefits and large, dispersed costs; the co-existence of pro-social actions (like charity donations) as well as welfare-damaging behavior (like tax evasion or insurance fraud); the effect of insurance protection on medical decision making; and fully congestible altruism where a single victim receives the same amount of donations than a group of needy individuals. 
Future research may address several issues that we do not consider in this paper. The number of payers we have in our experiment is still relatively small compared to the number of individuals affected in many real-world applications, such as the number of insurance holders or tax payers. It would be interesting to extend our analysis to field settings that allow for even larger numbers of payers. Next, an important question is why many subjects ignore the number of affected individuals. It may be possible to identify some of the mechanisms that we discussed in this paper. For example, providing detailed information about the identity of individual payers (or other framing manipulations), might be a promising method to influence and analyze the extent to which subjects are insensitive to group size, and to discover potential underlying causes of the insensitivity.

\section{References}

Andreoni, James, And Lise Vesterlund (2001): "Which is the Fair Sex? Gender Differences in Altruism," Quarterly Journal of Economics, 116(1), 293-312.

Andreoni, James, And John Miller (2002): "Giving According to GARP: An Experimental Test of the Consistency of Preferences for Altruism," Econometrica, 70(2), 737-753.

Andreoni, James (2007): "Giving Gifts to Groups: How Altruism Depends on the Number of Recipients," Journal of Public Economics, 91(9), 1731-1749.

Bateman, Ian, Alistair Munro, Bruce Rhodes, Chris Starmer, and Robert Sugden (1997): "Does Part-Whole Bias Exist? An Experimental Investigation," Economic Journal, 107(441), 322-332.

Bolton, Gary, And Axel Ockenfels (2000): "ERC: A Theory of Equity, Reciprocity, and Competition," American Economic Review, 90(1), 166-193.

Carson, Richard (2012): "Contingent Valuation: A Practical Alternative when Prices Aren't Available," Journal of Economic Perspectives, 26(4), 27-42.

Chandra, Amitabh, And Jonathan Skinner (2012): "Technology Growth and Expenditure Growth in Health Care," Journal of Economic Literature, 50(3), 645680.

Charness, Garry, and Matthew Rabin (2002): "Understanding Social Preferences with Simple Tests," Quarterly Journal of Economics, 117(3), 817-869. 
Cowell, Frank, Marc Fleurbaey, and Bertil Tungodden (2015): "The tyranny puzzle in social preferences: An empirical investigation," Social Choice and Welfare, 45(4), 765-792.

Cox, James, Daniel Friedman, and Steven GJerstad (2007): “A tractable model of reciprocity and fairness," Games and Economic Behavior, 59(1), 17-45.

Cox, James, And Vjollca Sadiraj (2012): "Direct Tests Of Individual Preferences For Efficiency And Equity," Economic Inquiry, 50(4), 920-931.

Desvousges, William, F. Reed Johnson, Richard Dunford, Sara Hudson, Nichole Wilson, And Kevin Boyle (1993): "Measuring Natural Resource Damages with Contingent Valuation: Tests of Validity and Reliability," In: Jerry A. Hausman (Ed.): Contingent valuation: A critical assessment. Amsterdam: North-Holland, 91-164, 1993.

Engel, Christoph (2011): "Dictator games: a meta study," Experimental Economics, 14(4), 583-610.

Engelmann, Dirk, And Martin Strobel (2004): "Inequality Aversion, Efficiency, and Maximin Preferences in Simple Distribution Experiments," American Economic Review, 94(4), 857-869.

Fehr, Ernst, and Klaus Schmidt (1999): "A Theory of Fairness, Competition and Cooperation," Quarterly Journal of Economics, 114(3), 817-868.

Fehr, ERnst, AND Klaus Schmidt (2006): "The Economics of Fairness, Reciprocity and Altruism - Experimental Evidence and New Theories," In: Serge-Christophe Kolm, Jean Mercier Ythier (Eds.): Handbook on the Economics of Giving, Reciprocity and Altruism, Elsevier, Amsterdam.

Fisman, Raymond, Shachar Kariv, and Daniel Markovits (2007): "Individual Preferences for Giving," American Economic Review, 97(5), 1858-1877.

Fisman, Raymond, Pamela Jakiela, and Shachar Kariv (2014): "The Distributional Preferences of Americans," NBER Working Paper No. 20145.

Fisman, Raymond, Pamela Jakiela, Shachar Kariv, and Daniel Markovits (2015): "The distributional preferences of an elite," Science, 349(6254).

Fleurbaey, Marc, And Bertil Tungodden (2010): "The Tyranny of NonAggregation versus the Tyranny of Aggregation in Social Cchoices: A Real Dilemma," Economic Theory, 44(3), 399-414. 
Frederick, Shane, And Baruch Fischhoff (1998): "Scope (in)sensitivity in Elicited Valuations," Risk, Decision, and Policy, 3(2), 109-123.

Greiner, Ben (2015): "Subject Pool Recruitment Procedures: Organizing Experiments with ORSEE," Journal of the Economic Science Association, 1(1), 114-125.

Güth, Werner, and Eric van Damme (1998): "Information, Strategic Behavior, and Fairness in Ultimatum Bargaining: An Experimental Study," Journal of Mathematical Psychology, 42(2-3), 227-247.

Hamilton, David, and Steven Sherman (1996): "Perceiving Persons and Groups," Psychological Review, 103(2), 336-355.

Hausman, Jerry (2012): "Contingent Valuation: From Dubious to Hopeless," Journal of Economic Perspectives, 26(4), 43-56.

Isaac, Mark, And James Walker (1988): "Group Size Effects in Public Goods Provision: The Voluntary Contributions Mechanism," Quarterly Journal of Economics, 103(1), 179-199.

IsaAc, Mark, James Walker, And Arlington Williams (1994): "Group size and the voluntary provision of public goods: Experimental evidence utilizing large groups," Journal of Public Economics, 54(1), 1-36.

Kahneman, Daniel, Ilana Ritov, and David Schkade (1999): "Economic Preferences or Attitude Expressions?: An Analysis of Dollar Responses to Public Issues," Journal of Risk and Uncertainty, 19(1), 203-235.

Kahneman, Daniel (2003): "Maps of Bounded Rationality: Psychology for Behavioral Economics," American Economic Review, 93(5), 1449-1475.

Kahneman, Daniel (2011): Thinking, Fast and Slow, Farrar, Straus and Giroux, New York.

Kemfert, Claudia, and Stefan Kooths (2008): "Die wirtschaftlichen Folgen von Bahnstreiks," DIW Wochenbericht, 75(3), 25-29.

Kogut, Tehila, And Ilana Ritov (2005): "The Singularity Effect of Identified Victims in Separate and Joint Evaluations," Organizational Behavior and Human Decision Processes, 97(2), 106-116.

Lifton, Robert (1967): Death in Life: Survivors of Hiroshima, Random House, New York. 
Mazar, Nina, On Amir, And Dan Ariely (2008): "The Dishonesty of Honest People: A Theory of Self-Concept Maintenance," Journal of Marketing Research, 45(6), 633-644.

McGuire, Thomas (2000): "Physician Agency." In: Anthony Cuyler, Joseph Newhouse (Eds.): Handbook of Health Economics, Vol. 1A, Amsterdam, North-Holland.

McKinlay, John, Deborah Potter, and Henry Feldman (1996): "Non-Medical Influences on Medical Decision-Making," Social Science and Medicine, 42(5), 769-776.

Mort, Elizabeth, Jennifer Edwards, David Emmons, Karen Convery, and David Blumenthal (1996): "Physician Response to Patient Insurance Status in Ambulatory Care Clinical Decision-Making: Implications for Quality Care," Medical Care, 34(8), 783-797.

Movsas, Tammy, Eden Wells, Ann Mongoven, and Violanda Grigorescu (2012): "Does Medical Insurance Type (Private vs Public) Influence the Physician's Decision to Perform Caesarean Delivery?," Journal of Medical Ethics, 38(8), 470-473.

Okada, Akira, And Arno Riedl (2005): "Inefficiency and social exclusion in a coalition formation game: experimental evidence," Games and Economic Behavior, 50(2), 278-311.

Olson, Mancur (1965): The Logic of Collective Action: Public Goods and the Theory of Groups, Harvard University Press.

Rischatsch, Maurus, Maria Trottmann, and Peter Zweifel (2013): “Generic Substitution, Financial Interests, and Imperfect Agency," International Journal of Health Care Finance and Economics, 13(2), 115-138.

Slovic, PAUl (2007): "If I look at the mass I will never act: Psychic numbing and genocide," Judgment and Decision Making, 2(2), 79-95.

Susskind, Joshua, Kristin Maurer, Vinia Thakkar, and David Sherman (1999): "Perceiving individuals and groups: Expectancies, dispositional inferences, and causal attributions," Journal of Personality and Social Psychology, 76(2), 181191.

Voorhoeve, Alex (2014): "How Should We Aggregate Competing Claims?," Ethics, $125(1), 64-87$. 


\section{Tables and Figures}

TABLE 1 - Payoff Parameters and

Pure Preference Type Actions

\begin{tabular}{ccccccc}
\hline \hline Game & $a$ & $b$ & $c$ & $x_{i}^{s}$ & $x_{i}^{w}$ & $x_{i}^{m}$ \\
\hline 1 & -1.0 & 1.5 & 0.0 & 0 & 10 & 4 \\
2 & -1.0 & 1.0 & 0.0 & 0 & any & 5 \\
3 & -1.0 & 0.5 & 0.0 & 0 & 0 & 6,7 \\
\hline 4 & 1.5 & 0.0 & 1.0 & 10 & 0 & any \\
5 & 1.0 & 0.0 & 1.0 & 10 & 0 & any \\
6 & 0.5 & 0.0 & 1.0 & 10 & 0 & any \\
\hline 7 & 1.0 & 0.0 & 0.8 & 10 & 0 & any \\
8 & 1.0 & 0.0 & 0.4 & 10 & 0 & any \\
9 & 1.0 & 0.0 & 0.2 & 10 & 0 & any \\
\hline 10 & 0.0 & 1.5 & 1.0 & any & 0 & 4 \\
11 & 0.0 & 1.0 & 1.0 & any & 0 & 5 \\
12 & 0.0 & 0.5 & 1.0 & any & 0 & 6,7 \\
\hline 13 & 0.0 & 1.0 & 0.8 & any & 0 & 6 \\
14 & 0.0 & 1.0 & 0.4 & any & 0 & 7 \\
15 & 0.0 & 1.0 & 0.2 & any & 0 & 9 \\
\hline 16 & 1.0 & 1.5 & 1.0 & 10 & 0 & 4 \\
17 & 1.0 & 1.0 & 1.0 & 10 & 0 & 5 \\
18 & 1.0 & 0.5 & 1.0 & 10 & 0 & 6,7 \\
\hline \hline
\end{tabular}


TABLE 2 - Behavior in Dispersed Costs Games with Decider Benefit

\begin{tabular}{|c|c|c|c|c|c|c|c|c|}
\hline \multirow[b]{2}{*}{ Variable } & \multirow{2}{*}{\multicolumn{3}{|c|}{$\begin{array}{c}\text { Prob. } \\
d^{+} \text {-type } \\
(3)\end{array}$}} & \multicolumn{2}{|c|}{$d^{+}$-type } & \multirow{2}{*}{$\begin{array}{c}\text { Selfish } \\
(6)\end{array}$} & \multirow{2}{*}{$\begin{array}{c}\text { Maximin } \\
(7)\end{array}$} & \multirow{2}{*}{$\begin{array}{c}\text { Other } \\
(8)\end{array}$} \\
\hline & & & & (4) & $(5)$ & & & \\
\hline $\mathrm{a}$ & $\begin{array}{c}1.227^{* * *} \\
{[0.112]}\end{array}$ & $\begin{array}{c}1.183^{* * *} \\
{[0.173]}\end{array}$ & & $\begin{array}{c}1.252^{* * *} \\
{[0.173]}\end{array}$ & $\begin{array}{c}1.464^{* * *} \\
{[0.254]}\end{array}$ & $\begin{array}{c}1.272^{* * *} \\
{[0.186]}\end{array}$ & $\begin{array}{c}0.901^{* *} \\
{[0.357]}\end{array}$ & $\begin{array}{c}1.549^{* * *} \\
{[0.304]}\end{array}$ \\
\hline $\mathrm{c}$ & $\begin{array}{c}-2.634^{* * *} \\
{[0.192]}\end{array}$ & $\begin{array}{c}-1.874^{* * *} \\
{[0.462]}\end{array}$ & & $\begin{array}{c}-2.898^{* * *} \\
{[0.266]}\end{array}$ & $\begin{array}{c}-3.118^{* * *} \\
{[0.600]}\end{array}$ & $\begin{array}{c}-1.659^{* * *} \\
{[0.291]}\end{array}$ & $\begin{array}{c}-1.714^{* * *} \\
{[0.575]}\end{array}$ & $\begin{array}{c}-4.728^{* * *} \\
{[0.435]}\end{array}$ \\
\hline $\mathrm{P} 1$ & $\begin{array}{c}1.677^{* * *} \\
{[0.449]}\end{array}$ & $\begin{array}{c}0.919 \\
{[0.703]}\end{array}$ & $\begin{array}{c}0.079 \\
{[0.066]}\end{array}$ & $\begin{array}{c}1.110^{* *} \\
{[0.436]}\end{array}$ & $\begin{array}{c}0.527 \\
{[0.773]}\end{array}$ & $\begin{array}{c}1.169^{* *} \\
{[0.576]}\end{array}$ & $\begin{array}{l}-0.253 \\
{[1.937]}\end{array}$ & $\begin{array}{c}2.879 * * * \\
{[0.861]}\end{array}$ \\
\hline $\mathrm{P} 4$ & $\begin{array}{c}0.538 \\
{[0.460]}\end{array}$ & $\begin{array}{c}2.616^{* * *} \\
{[0.668]}\end{array}$ & $\begin{array}{l}-0.028 \\
{[0.063]}\end{array}$ & $\begin{array}{l}-0.504 \\
{[0.489]}\end{array}$ & $\begin{array}{c}1.115 \\
{[0.895]}\end{array}$ & $\begin{array}{c}0.571 \\
{[0.659]}\end{array}$ & $\begin{array}{c}0.568 \\
{[1.675]}\end{array}$ & $\begin{array}{c}0.517 \\
{[0.667]}\end{array}$ \\
\hline P8 & $\begin{array}{c}0.771 \\
{[0.509]}\end{array}$ & $\begin{array}{c}2.143^{* * *} \\
{[0.706]}\end{array}$ & $\begin{array}{l}-0.094 \\
{[0.063]}\end{array}$ & $\begin{array}{l}-0.590 \\
{[0.545]}\end{array}$ & $\begin{array}{l}-0.549 \\
{[1.018]}\end{array}$ & $\begin{array}{c}1.061 \\
{[0.643]}\end{array}$ & $\begin{array}{c}1.518 \\
{[1.809]}\end{array}$ & $\begin{array}{l}-0.428 \\
{[0.799]}\end{array}$ \\
\hline P16 & $\begin{array}{c}0.623 \\
{[0.400]}\end{array}$ & $\begin{array}{l}1.118^{*} \\
{[0.644]}\end{array}$ & $\begin{array}{c}0.031 \\
{[0.050]}\end{array}$ & $\begin{array}{l}-0.020 \\
{[0.422]}\end{array}$ & $\begin{array}{l}-0.224 \\
{[0.834]}\end{array}$ & $\begin{array}{c}0.261 \\
{[0.585]}\end{array}$ & $\begin{array}{l}-1.569 \\
{[0.979]}\end{array}$ & $\begin{array}{c}1.746^{* *} \\
{[0.826]}\end{array}$ \\
\hline Male & $\begin{array}{c}0.156 \\
{[0.302]}\end{array}$ & $\begin{array}{c}0.155 \\
{[0.302]}\end{array}$ & $\begin{array}{c}-0.173^{* * *} \\
{[0.039]}\end{array}$ & $\begin{array}{c}-0.666^{*} \\
{[0.339]}\end{array}$ & $\begin{array}{c}-0.666^{*} \\
{[0.340]}\end{array}$ & $\begin{array}{c}0.615 \\
{[0.397]}\end{array}$ & $\begin{array}{l}-0.291 \\
{[1.013]}\end{array}$ & $\begin{array}{l}-0.556 \\
{[0.547]}\end{array}$ \\
\hline $\mathrm{a} * \mathrm{P} 1$ & & $\begin{array}{c}1.547^{* * *} \\
{[0.474]}\end{array}$ & & & $\begin{array}{c}0.472 \\
{[0.622]}\end{array}$ & & & \\
\hline $\mathrm{a} * \mathrm{P} 4$ & & $\begin{array}{l}-0.247 \\
{[0.295]}\end{array}$ & & & $\begin{array}{c}-1.271^{* * *} \\
{[0.470]}\end{array}$ & & & \\
\hline $\mathrm{a} * \mathrm{P} 8$ & & $\begin{array}{l}-0.559 \\
{[0.344]}\end{array}$ & & & $\begin{array}{l}-0.686 \\
{[0.418]}\end{array}$ & & & \\
\hline $\mathrm{a} * \mathrm{P} 16$ & & $\begin{array}{l}-0.195 \\
{[0.259]}\end{array}$ & & & $\begin{array}{l}-0.206 \\
{[0.430]}\end{array}$ & & & \\
\hline$c^{*} \mathrm{P} 1$ & & $\begin{array}{l}-0.983 \\
{[0.630]}\end{array}$ & & & $\begin{array}{c}0.121 \\
{[0.821]}\end{array}$ & & & \\
\hline$c^{*} \mathrm{P} 4$ & & $\begin{array}{c}-2.404^{* * *} \\
{[0.694]}\end{array}$ & & & $\begin{array}{l}-0.506 \\
{[0.932]}\end{array}$ & & & \\
\hline$c^{*} \mathrm{P} 8$ & & $\begin{array}{l}-1.015 \\
{[0.656]}\end{array}$ & & & $\begin{array}{c}0.848 \\
{[1.067]}\end{array}$ & & & \\
\hline$c * \mathrm{P} 16$ & & $\begin{array}{l}-0.311 \\
{[0.548]}\end{array}$ & & & $\begin{array}{c}0.530 \\
{[0.744]}\end{array}$ & & & \\
\hline Constant & $\begin{array}{c}5.938^{* * *} \\
{[0.359]}\end{array}$ & $\begin{array}{c}5.357^{* * *} \\
{[0.534]}\end{array}$ & $\begin{array}{c}0.428^{* * *} \\
{[0.038]}\end{array}$ & $\begin{array}{c}7.601^{* * *} \\
{[0.386]}\end{array}$ & $\begin{array}{c}7.575^{* * *} \\
{[0.634]}\end{array}$ & $\begin{array}{c}7.332^{* * *} \\
{[0.577]}\end{array}$ & $\begin{array}{c}3.213^{* * *} \\
{[1.182]}\end{array}$ & $\begin{array}{c}5.510^{* * *} \\
{[0.773]}\end{array}$ \\
\hline Observations & 3,069 & 3,069 & 581 & 1,093 & 1,093 & 1,071 & 247 & 618 \\
\hline R-squared & 0.074 & 0.080 & 0.040 & 0.149 & 0.153 & 0.066 & 0.112 & 0.250 \\
\hline
\end{tabular}

Note: This table shows the results of ordinary least squares regressions using the data from the dispersed costs games with decider benefit (Games 4 to 9 ). The dependent variables are the number of units provided for the whole sample in Columns 1 and 2; a dummy that indicates whether a subject is classified as $d^{+}$type in Column 3; and the number of units provided for the subsamples of $d^{+}$-types (Columns 4 and 5), the selfish types (Column 6), the maximin types (Column 7), and everybody who is not part of any of the former groups (Column 8). Independent variables are the parameters $a$ and $c$, a gender dummy, and dummies for the treatments P1 to P16. The reference treatment is P32. Robust standard errors in brackets, clustering of standard errors by respondent. ${ }^{* * *} \mathrm{p}<0.01,{ }^{*} \mathrm{p}<0.05,{ }^{*} \mathrm{p}<0.1$. See the Online Appendix for a regression analysis of the behavior of selfish, maximin and other types including interaction terms. 
TABLE 3 - Behavior in Dispersed Costs Games with Receiver Benefit

\begin{tabular}{|c|c|c|c|c|c|c|c|c|}
\hline \multirow[b]{2}{*}{ Variable } & \multirow{2}{*}{\multicolumn{3}{|c|}{$\begin{array}{c}\text { Prob. } \\
r^{+} \text {-type } \\
(3)\end{array}$}} & \multicolumn{2}{|c|}{$r^{+}$-type } & \multirow{2}{*}{$\begin{array}{c}\text { Selfish } \\
(6)\end{array}$} & \multirow{2}{*}{$\begin{array}{c}\text { Maximin } \\
(7)\end{array}$} & \multirow{2}{*}{$\begin{array}{c}\text { Other } \\
(8)\end{array}$} \\
\hline & & & & $(4)$ & (5) & & & \\
\hline \multirow[t]{2}{*}{$\mathrm{b}$} & 0.074 & -0.269 & & $-0.391^{* *}$ & $-0.450^{*}$ & 0.163 & $-1.468^{* * *}$ & $1.058^{* * *}$ \\
\hline & {$[0.125]$} & [0.181] & & {$[0.152]$} & {$[0.244]$} & {$[0.231]$} & {$[0.276]$} & {$[0.277]$} \\
\hline \multirow[t]{2}{*}{ c } & $-3.655^{* * *}$ & $-2.890 * * *$ & & $-3.327^{* * *}$ & $-3.080 * * *$ & $-2.805^{* * *}$ & $-3.748^{* * *}$ & $-5.066^{* * *}$ \\
\hline & {$[0.183]$} & [0.443] & & {$[0.238]$} & [0.530] & {$[0.346]$} & [0.355] & {$[0.376]$} \\
\hline \multirow[t]{2}{*}{$\mathrm{P} 1$} & $2.373^{* * *}$ & $1.415^{* *}$ & 0.097 & $0.642^{* *}$ & 0.813 & $4.067^{* * *}$ & 0.508 & $2.421^{* * *}$ \\
\hline & [0.264] & {$[0.715]$} & {$[0.067]$} & {$[0.286]$} & {$[0.865]$} & [0.543] & {$[0.437]$} & [0.460] \\
\hline \multirow[t]{2}{*}{$\mathrm{P} 4$} & $0.559^{*}$ & $2.068^{* * *}$ & -0.040 & -0.158 & 0.835 & $1.460^{* *}$ & -0.410 & 0.751 \\
\hline & {$[0.291]$} & {$[0.655]$} & {$[0.063]$} & {$[0.288]$} & {$[0.839]$} & {$[0.573]$} & {$[0.448]$} & {$[0.465]$} \\
\hline \multirow[t]{2}{*}{ P8 } & -0.087 & 0.209 & $-0.174^{* * *}$ & 0.390 & -0.534 & 0.730 & 0.452 & -0.417 \\
\hline & {$[0.375]$} & {$[0.769]$} & {$[0.062]$} & {$[0.395]$} & {$[1.118]$} & {$[0.641]$} & {$[0.927]$} & {$[0.654]$} \\
\hline \multirow[t]{2}{*}{ P16 } & -0.057 & 0.204 & -0.069 & -0.181 & -0.119 & $0.844^{*}$ & -0.947 & -0.418 \\
\hline & {$[0.270]$} & {$[0.661]$} & {$[0.050]$} & {$[0.269]$} & {$[0.767]$} & {$[0.492]$} & {$[0.681]$} & {$[0.568]$} \\
\hline \multirow[t]{2}{*}{ Male } & $-0.850^{* * *}$ & $-0.852^{* * *}$ & $-0.190^{* * *}$ & -0.170 & -0.174 & $-0.684^{*}$ & -0.506 & $-0.622^{*}$ \\
\hline & {$[0.202]$} & [0.203] & [0.039] & {$[0.203]$} & {$[0.204]$} & {$[0.374]$} & {$[0.600]$} & {$[0.368]$} \\
\hline \multirow[t]{2}{*}{$\mathrm{b} * \mathrm{P} 1$} & & $1.607^{* * *}$ & & & 0.089 & & & \\
\hline & & {$[0.580]$} & & & {$[0.527]$} & & & \\
\hline \multirow[t]{2}{*}{$\mathrm{b} * \mathrm{P} 4$} & & 0.282 & & & -0.343 & & & \\
\hline & & {$[0.308]$} & & & {$[0.384]$} & & & \\
\hline \multirow[t]{2}{*}{$\mathrm{b} * \mathrm{P} 8$} & & 0.443 & & & 0.762 & & & \\
\hline & & {$[0.343]$} & & & {$[0.536]$} & & & \\
\hline \multirow[t]{2}{*}{$\mathrm{b} * \mathrm{P} 16$} & & 0.169 & & & 0.135 & & & \\
\hline & & {$[0.292]$} & & & {$[0.390]$} & & & \\
\hline \multirow[t]{2}{*}{$\mathrm{c} * \mathrm{P} 1$} & & -0.791 & & & -0.320 & & & \\
\hline & & {$[0.625]$} & & & {$[0.689]$} & & & \\
\hline \multirow[t]{2}{*}{$c^{*} \mathrm{P} 4$} & & $-2.348^{* * *}$ & & & -0.852 & & & \\
\hline & & [0.623] & & & {$[0.817]$} & & & \\
\hline \multirow[t]{2}{*}{$c * \mathrm{P} 8$} & & -0.914 & & & 0.254 & & & \\
\hline & & {$[0.650]$} & & & [1.104] & & & \\
\hline \multirow[t]{2}{*}{$\mathrm{c} * \mathrm{P} 16$} & & -0.493 & & & -0.236 & & & \\
\hline & & {$[0.524]$} & & & {$[0.652]$} & & & \\
\hline \multirow[t]{2}{*}{ Constant } & $6.964^{* * *}$ & $6.678^{* * *}$ & $0.485^{* * *}$ & $8.546^{* * *}$ & $8.401^{* * *}$ & $4.597^{* * *}$ & $10.295^{* * *}$ & $6.659^{* * *}$ \\
\hline & {$[0.291]$} & {$[0.507]$} & {$[0.039]$} & {$[0.325]$} & {$[0.621]$} & {$[0.587]$} & {$[0.475]$} & {$[0.498]$} \\
\hline Observations & 3,168 & 3,168 & 581 & 1,161 & 1,161 & 1,116 & 261 & 669 \\
\hline R-squared & 0.207 & 0.215 & 0.059 & 0.231 & 0.234 & 0.193 & 0.315 & 0.342 \\
\hline
\end{tabular}

Note: This table shows the results of ordinary least squares regressions using the data from the dispersed costs games with receiver benefit (Games 10 to 15). The dependent variables are the number of units provided for the whole sample in Columns 1 and 2; a dummy that indicates whether a subject is classified as $r^{+}$-type in Column 3; and the number of units provided for the subsamples of $r^{+}$-type types (Columns 4 and 5), the selfish types (Column 6), the maximin types (Column 7), and everybody who is not part of any of the former groups (Column 8). Independent variables are the parameters $a$ and $c$, a gender dummy, and dummies for the treatments P1 to P16. The reference treatment is P32. Robust standard errors in brackets, clustering of standard errors by respondent. ${ }^{* * *} \mathrm{p}<0.01,{ }^{* *} \mathrm{p}<0.05,{ }^{*} \mathrm{p}<0.1$. See the Online Appendix for a regression analysis of the behavior of selfish, maximin and other types including interaction terms. 
TABLE 4 - Reversals in Behavior

\begin{tabular}{|c|c|c|c|c|c|c|}
\hline P32 Game 9 & $\begin{array}{c}\text { selfish } \\
{[\varnothing g e n=0.00]}\end{array}$ & $\begin{array}{c}\text { non-selfish } \\
{[\varnothing \text { gen }=15.47]}\end{array}$ & t-sig. & $\begin{array}{c}\text { top } 25 \\
\text { generosity } \\
{[\varnothing \text { gen }=29.45]}\end{array}$ & $\begin{array}{c}\text { bottom } 75 \\
\text { generosity } \\
{[\varnothing g e n=4.35]}\end{array}$ & t-sig. \\
\hline mean (sd) & $8.93(2.84)$ & $5.96(4.20)$ & $* * *$ & $3.93(4.12)$ & $8.04(3.40)$ & $* * *$ \\
\hline share zero & 0.07 & 0.20 & $*$ & 0.34 & 0.09 & $* * *$ \\
\hline share ten & 0.86 & 0.43 & $* * *$ & 0.24 & 0.69 & $* * *$ \\
\hline P32 Game 15 & $\begin{array}{c}\text { top } 25 \\
\text { welfare } \\
{[\varnothing w e l=16.48]}\end{array}$ & $\begin{array}{c}\text { bottom } 75 \\
\text { welfare } \\
{[\varnothing w e l=42.80]}\end{array}$ & t-sig. & $\begin{array}{c}\text { top } 25 \\
\text { maximin } \\
{[\varnothing \max =1.05]}\end{array}$ & $\begin{array}{c}\text { bottom } 75 \\
\text { maximin } \\
{[\varnothing \max =23.51]}\end{array}$ & t-sig. \\
\hline mean (sd) & $5.52(3.70)$ & $5.62(3.71)$ & - & $7.66(1.59)$ & $4.72(3.97)$ & $* * *$ \\
\hline share zero & 0.20 & 0.25 & - & 0.00 & 0.33 & $* * *$ \\
\hline share nine/ten & 0.20 & 0.22 & - & 0.24 & 0.20 & - \\
\hline
\end{tabular}




\section{Appendix: Alternative Social Preference Models}

We examine the predictions of several prominent social preference models for our dispersed costs games. Throughout we assume that the parties' endowments are such that $W_{D}=W_{P}>W_{R}$. We say that a model does not capture $d$-insensitivity ( $r$-insensitivity) to group size if for almost all values of the preference parameters we cannot find an dispersed costs game with decider (receiver) benefit in which the decider provides positive amounts the good, regardless of the number of payers.

Fehr and Schmidt (1999). If the decider has Fehr and Schmidt (1999) preferences, her utility function is given by

$$
\begin{aligned}
U^{F S}\left(\pi_{D}, \pi_{R}, \pi_{P}\right)= & \pi_{D}-\alpha \frac{1}{n+1} \max \left\{0, \pi_{R}-\pi_{D}\right\}-\beta \frac{1}{n+1} \max \left\{0, \pi_{D}-\pi_{R}\right\} \\
& -\alpha \frac{n}{n+1} \max \left\{0, \pi_{P}-\pi_{D}\right\}-\beta \frac{n}{n+1} \max \left\{0, \pi_{D}-\pi_{P}\right\},
\end{aligned}
$$

where $\beta \leq \alpha$ and $0 \leq \beta<1$. Parameter $\alpha$ captures the decider's aversion to disadvantageous inequality, while $\beta$ captures her aversion to advantageous inequality. In a dispersed costs game with decider benefit, the marginal utility from providing the good equals

$$
\frac{\partial U^{F S}}{\partial x}=a-\beta \frac{n}{n+1}(a+c) .
$$

For generic values of $\beta$, the decider provides nothing or the maximal amount of the good. Since $\beta<1$, we can always find a dispersed costs game $(a, 0, c)$ in which the decider provides the maximal amount, regardless of the number of payers. Thus, the model captures $d$-insensitivity to group size. In a dispersed costs game with receiver benefit, the marginal utility from providing the good (as long as the receiver's payoff does not exceed the decider's payoff) is

$$
\frac{\partial U^{F S}}{\partial x}=\beta \frac{1}{n+1} b-\beta \frac{n}{n+1} c .
$$

If $\beta>0$ and the number of payers is sufficiently large, the decider provides nothing of the good. The Fehr and Schmidt (1999) preference model therefore does not capture $r$-insensitivity to group size.

Bolton and Ockenfels (2000). If the decider has Bolton and Ockenfels (2000) preferences, her utility function is given by

$$
U^{B O}\left(\pi_{D}, \pi_{R}, \pi_{P}\right)=V\left(\pi_{D}, \sigma\right) \text { with } \sigma=\frac{\pi_{D}}{\pi_{D}+\pi_{R}+n \pi_{P}} .
$$

In the model, it is assumed that $V$ is twice differentiable in both arguments and that for given $\pi_{D}$ it attains its global maximum at $\sigma=\frac{1}{n+2}$ (i.e., for given $\pi_{D}$ the decider's utility is maximal if she gets the average payoff). These properties imply that in any 
dispersed costs game $(0, b, c)$ we have

$$
\frac{\partial U^{B O}}{\partial x}=\frac{\partial V\left(\pi_{D}, \sigma\right)}{\partial \sigma} \times \frac{-\pi_{D}(b-n c)}{\left(\pi_{D}+\pi_{R}+n \pi_{P}\right)^{2}} .
$$

If the provision of the good lowers the group payoff, $b-n c<0$, then for any $x$ the first term is negative (since the provision of the good increases the decider's share in the group payoff), while the second term is positive. It is then optimal for the decider to provide nothing of the good. Hence, the model does not capture $r$-insensitivity to group size. Unfortunately, the model does not make any predictions about behavior in dispersed costs games with decider benefit without further assumptions on $V$.

Charness and Rabin (2002). If the decider has Charness and Rabin (2002) preferences, her utility function is given by

$$
U^{C R}\left(\pi_{D}, \pi_{R}, \pi_{P}\right)=(1-\lambda) \pi_{D}+\lambda\left[\delta \min \left\{\pi_{D}, \pi_{R}, \pi_{P}\right\}+(1-\delta)\left(\pi_{D}+\pi_{R}+n \pi_{P}\right)\right],
$$

where the parameters $\delta, \lambda$ take on values in the unit interval. Parameter $\lambda$ captures concerns for the payoff of others, while $\delta$ captures how important the payoff of the least well-off individual is relative to the group payoff. In a dispersed costs game $(a, 0, c)$, the marginal utility from providing the good is

$$
\frac{\partial U^{C R}}{\partial x}=(1-\lambda) a+\lambda(1-\delta)(a-n c),
$$

while in a dispersed costs game $(0, b, c)$, the marginal utility from providing the good is given by

$$
\frac{\partial U^{C R}}{\partial x} \leq \lambda[\delta b+(1-\delta)(b-n c)]
$$

In both cases, the marginal utility from providing the good is strictly negative if $\lambda>0$, $\delta<1$ and the number of payers is sufficiently large. Hence, the model does not capture $d$ - and $r$-insensitivity to group size. 


\section{Appendix: Behavior in all Games and Treatments}

TABLE 5 - Average behavior in all games

\begin{tabular}{|c|c|c|c|c|c|c|c|c|}
\hline $\begin{array}{l}\text { Treat- } \\
\text { ment } \\
\text { [share] }\end{array}$ & Game & mean $(\mathrm{sd})$ & $\begin{array}{c}\text { share } \\
\text { ten }\end{array}$ & $\begin{array}{c}\text { share } \\
\text { zero }\end{array}$ & $\begin{array}{c}\text { mean } \\
d^{+} \text {-type } \\
{[0.43]}\end{array}$ & $\begin{array}{c}\text { mean } \\
r^{+} \text {-type } \\
{[0.49]}\end{array}$ & $\begin{array}{c}\text { mean } \\
\text { selfish } \\
{[0.31]}\end{array}$ & $\begin{array}{c}\text { mean } \\
\text { maximin } \\
{[0.05]}\end{array}$ \\
\hline $\mathrm{P} 1$ & 1 & $2.63(2.97)$ & 0.08 & 0.39 & 3.25 & 3.05 & 0.00 & 4.00 \\
\hline $\mathrm{P} 1$ & 2 & $1.92(2.20)$ & 0.00 & 0.47 & 2.41 & 2.68 & 0.00 & 5.00 \\
\hline $\mathrm{P} 1$ & 3 & $1.40(2.15)$ & 0.00 & 0.60 & 1.84 & 2.05 & 0.00 & 6.25 \\
\hline $\mathrm{P} 1$ & 4 & $7.49(3.43)$ & 0.54 & 0.07 & 7.81 & 6.67 & 9.74 & 2.75 \\
\hline $\mathrm{P} 1$ & 5 & $6.50(3.75)$ & 0.41 & 0.14 & 6.94 & 5.92 & 8.74 & 2.75 \\
\hline $\mathrm{P} 1$ & 6 & $4.76(4.21)$ & 0.31 & 0.31 & 5.87 & 4.92 & 7.30 & 0.50 \\
\hline $\mathrm{P} 1$ & 7 & $6.74(3.68)$ & 0.45 & 0.08 & 7.03 & 5.89 & 8.83 & 3.00 \\
\hline $\mathrm{P} 1$ & 8 & $7.78(3.41)$ & 0.64 & 0.08 & 8.55 & 7.36 & 9.04 & 2.75 \\
\hline $\mathrm{P} 1$ & 9 & $8.64(2.86)$ & 0.74 & 0.04 & 9.29 & 8.42 & 9.61 & 3.00 \\
\hline $\mathrm{P} 1$ & 10 & $5.97(2.83)$ & 0.27 & 0.03 & 5.58 & 5.28 & 6.57 & 4.25 \\
\hline $\mathrm{P} 1$ & 11 & $5.30(1.94)$ & 0.09 & 0.04 & 5.39 & 5.33 & 5.70 & 6.25 \\
\hline $\mathrm{P} 1$ & 12 & $4.64(3.31)$ & 0.11 & 0.26 & 5.65 & 5.64 & 5.17 & 5.25 \\
\hline $\mathrm{P} 1$ & 13 & $6.28(2.33)$ & 0.19 & 0.03 & 6.19 & 5.94 & 6.39 & 5.75 \\
\hline $\mathrm{P} 1$ & 14 & $7.50(2.42)$ & 0.34 & 0.04 & 7.45 & 7.33 & 6.91 & 7.75 \\
\hline $\mathrm{P} 1$ & 15 & $8.28(2.38)$ & 0.47 & 0.04 & 8.13 & 8.19 & 7.74 & 8.75 \\
\hline $\mathrm{P} 1$ & 16 & $8.05(2.64)$ & 0.59 & 0.00 & 7.29 & 6.81 & 10.00 & 5.75 \\
\hline $\mathrm{P} 1$ & 17 & $8.05(2.51)$ & 0.54 & 0.00 & 7.35 & 6.89 & 9.96 & 5.50 \\
\hline $\mathrm{P} 1$ & 18 & $8.16(2.35)$ & 0.53 & 0.00 & 7.94 & 7.31 & 9.96 & 5.50 \\
\hline [share] & & & & & [0.33] & {$[0.37]$} & {$[0.36]$} & {$[0.06]$} \\
\hline $\mathrm{P} 4$ & 1 & $2.00(2.28)$ & 0.03 & 0.44 & 2.65 & 3.10 & 0.00 & 4.00 \\
\hline $\mathrm{P} 4$ & 2 & $2.24(2.28)$ & 0.00 & 0.42 & 2.77 & 3.03 & 0.00 & 5.00 \\
\hline $\mathrm{P} 4$ & 3 & $1.65(2.28)$ & 0.00 & 0.60 & 2.35 & 2.59 & 0.00 & 6.00 \\
\hline $\mathrm{P} 4$ & 4 & $5.29(3.68)$ & 0.29 & 0.18 & 5.27 & 4.45 & 8.32 & 2.20 \\
\hline $\mathrm{P} 4$ & 5 & $4.88(3.85)$ & 0.28 & 0.23 & 5.31 & 4.10 & 7.71 & 2.80 \\
\hline $\mathrm{P} 4$ & 6 & $4.36(4.05)$ & 0.27 & 0.31 & 5.08 & 4.14 & 6.96 & 2.40 \\
\hline $\mathrm{P} 4$ & 7 & $5.06(3.72)$ & 0.28 & 0.18 & 5.27 & 4.31 & 7.79 & 3.00 \\
\hline $\mathrm{P} 4$ & 8 & $6.83(3.61)$ & 0.45 & 0.08 & 6.77 & 5.72 & 8.96 & 4.20 \\
\hline $\mathrm{P} 4$ & 9 & $8.55(3.06)$ & 0.77 & 0.05 & 8.42 & 7.69 & 9.71 & 5.60 \\
\hline $\mathrm{P} 4$ & 10 & $3.24(2.30)$ & 0.04 & 0.22 & 4.19 & 4.31 & 2.68 & 4.00 \\
\hline $\mathrm{P} 4$ & 11 & $3.59(2.45)$ & 0.03 & 0.23 & 4.42 & 4.66 & 3.07 & 5.00 \\
\hline $\mathrm{P} 4$ & 12 & $3.23(2.86)$ & 0.01 & 0.36 & 4.50 & 5.10 & 2.50 & 5.60 \\
\hline $\mathrm{P} 4$ & 13 & $3.88(2.36)$ & 0.03 & 0.18 & 4.58 & 4.66 & 2.93 & 5.40 \\
\hline $\mathrm{P} 4$ & 14 & $5.46(3.03)$ & 0.08 & 0.15 & 6.08 & 6.07 & 4.21 & 6.20 \\
\hline $\mathrm{P} 4$ & 15 & $8.13(2.73)$ & 0.47 & 0.06 & 7.88 & 8.34 & 7.68 & 7.20 \\
\hline $\mathrm{P} 4$ & 16 & $5.74(3.35)$ & 0.31 & 0.10 & 5.35 & 5.45 & 7.86 & 4.20 \\
\hline $\mathrm{P} 4$ & 17 & $6.09(3.21)$ & 0.32 & 0.08 & 5.88 & 5.90 & 8.00 & 5.20 \\
\hline $\mathrm{P} 4$ & 18 & $5.96(3.40)$ & 0.32 & 0.10 & 5.88 & 5.79 & 7.32 & 6.20 \\
\hline
\end{tabular}


TABLE 5 (continuation) - Average behavior in all games

\begin{tabular}{|c|c|c|c|c|c|c|c|c|}
\hline $\begin{array}{l}\text { Treat- } \\
\text { ment } \\
\text { [share] }\end{array}$ & Game & mean (sd) & $\begin{array}{c}\text { share } \\
\text { ten }\end{array}$ & $\begin{array}{c}\text { share } \\
\text { zero }\end{array}$ & $\begin{array}{c}\text { mean } \\
d^{+} \text {-type } \\
{[0.26]}\end{array}$ & $\begin{array}{c}\text { mean } \\
r^{+} \text {-type } \\
{[0.23]}\end{array}$ & $\begin{array}{c}\text { mean } \\
\text { selfish } \\
{[0.42]}\end{array}$ & $\begin{array}{c}\text { mean } \\
\text { maximin } \\
{[0.09]}\end{array}$ \\
\hline P8 & 1 & $2.03(2.62)$ & 0.04 & 0.51 & 2.39 & 2.81 & 0.00 & 4.00 \\
\hline P8 & 2 & $2.20(2.49)$ & 0.01 & 0.46 & 2.89 & 3.69 & 0.00 & 5.00 \\
\hline $\mathrm{P} 8$ & 3 & $1.90(2.61)$ & 0.01 & 0.54 & 2.94 & 3.00 & 0.00 & 6.33 \\
\hline P8 & 4 & $5.72(4.22)$ & 0.42 & 0.23 & 6.17 & 5.00 & 8.69 & 4.33 \\
\hline P8 & 5 & $5.33(4.23)$ & 0.36 & 0.26 & 4.89 & 4.50 & 8.52 & 4.33 \\
\hline P8 & 6 & $5.10(4.19)$ & 0.33 & 0.26 & 5.39 & 4.81 & 7.76 & 2.33 \\
\hline P8 & 7 & $5.70(4.10)$ & 0.39 & 0.17 & 5.17 & 5.69 & 8.45 & 2.67 \\
\hline $\mathrm{P} 8$ & 8 & $6.54(3.65)$ & 0.42 & 0.12 & 5.83 & 5.56 & 9.14 & 5.67 \\
\hline P8 & 9 & $8.03(3.27)$ & 0.64 & 0.09 & 7.83 & 7.31 & 9.79 & 6.33 \\
\hline P8 & 10 & $3.01(3.00)$ & 0.09 & 0.39 & 4.06 & 5.44 & 2.21 & 5.00 \\
\hline P8 & 11 & $3.03(3.11)$ & 0.07 & 0.41 & 3.83 & 5.56 & 2.41 & 4.67 \\
\hline $\mathrm{P} 8$ & 12 & $2.84(3.25)$ & 0.07 & 0.46 & 3.67 & 5.13 & 2.31 & 6.00 \\
\hline $\mathrm{P} 8$ & 13 & $3.49(2.96)$ & 0.07 & 0.28 & 4.11 & 5.44 & 2.79 & 6.00 \\
\hline P8 & 14 & $4.93(3.42)$ & 0.12 & 0.26 & 6.44 & 7.19 & 4.03 & 7.50 \\
\hline P8 & 15 & $6.17(3.75)$ & 0.28 & 0.20 & 7.28 & 7.50 & 5.00 & 9.00 \\
\hline $\mathrm{P} 8$ & 16 & $6.12(3.65)$ & 0.39 & 0.13 & 4.67 & 5.69 & 8.69 & 4.17 \\
\hline P8 & 17 & $6.42(3.52)$ & 0.39 & 0.12 & 5.44 & 6.63 & 8.59 & 5.83 \\
\hline P8 & 18 & $6.16(3.64)$ & 0.38 & 0.12 & 4.50 & 5.56 & 8.93 & 5.83 \\
\hline [share] & & & & & {$[0.39]$} & {$[0.34]$} & {$[0.39]$} & {$[0.08]$} \\
\hline $\mathrm{P} 16$ & 1 & $1.85(2.29)$ & 0.03 & 0.48 & 2.26 & 2.67 & 0.00 & 4.00 \\
\hline P16 & 2 & $1.83(2.10)$ & 0.00 & 0.49 & 2.44 & 2.72 & 0.00 & 5.00 \\
\hline $\mathrm{P} 16$ & 3 & $1.89(2.40)$ & 0.00 & 0.51 & 2.94 & 2.96 & 0.00 & 6.38 \\
\hline P16 & 4 & $5.86(4.07)$ & 0.41 & 0.19 & 6.52 & 5.20 & 7.92 & 0.92 \\
\hline $\mathrm{P} 16$ & 5 & $5.53(4.05)$ & 0.37 & 0.19 & 5.98 & 4.67 & 7.82 & 0.85 \\
\hline $\mathrm{P} 16$ & 6 & $4.87(4.08)$ & 0.31 & 0.24 & 5.26 & 4.04 & 7.07 & 0.77 \\
\hline P16 & 7 & $5.31(3.67)$ & 0.28 & 0.15 & 5.86 & 4.90 & 7.68 & 1.25 \\
\hline $\mathrm{P} 16$ & 8 & $6.33(3.90)$ & 0.44 & 0.16 & 7.02 & 5.63 & 8.26 & 1.46 \\
\hline $\mathrm{P} 16$ & 9 & $7.38(3.76)$ & 0.59 & 0.12 & 8.23 & 7.02 & 8.93 & 1.92 \\
\hline P16 & 10 & $3.13(2.64)$ & 0.06 & 0.28 & 3.73 & 4.44 & 2.71 & 3.31 \\
\hline P16 & 11 & $3.08(2.64)$ & 0.02 & 0.33 & 3.73 & 4.78 & 2.50 & 4.00 \\
\hline $\mathrm{P} 16$ & 12 & $3.23(3.03)$ & 0.03 & 0.36 & 3.68 & 4.76 & 2.56 & 5.00 \\
\hline $\mathrm{P} 16$ & 13 & $3.43(2.73)$ & 0.03 & 0.28 & 4.40 & 5.07 & 2.70 & 4.00 \\
\hline $\mathrm{P} 16$ & 14 & $4.83(3.20)$ & 0.09 & 0.19 & 5.81 & 6.39 & 3.70 & 6.00 \\
\hline $\mathrm{P} 16$ & 15 & $6.02(3.59)$ & 0.19 & 0.18 & 7.05 & 7.44 & 4.92 & 7.31 \\
\hline P16 & 16 & $5.90(3.33)$ & 0.31 & 0.08 & 5.61 & 5.07 & 7.82 & 3.77 \\
\hline $\mathrm{P} 16$ & 17 & $5.99(3.53)$ & 0.35 & 0.12 & 5.85 & 5.52 & 7.68 & 4.08 \\
\hline $\mathrm{P} 16$ & 18 & $5.93(3.63)$ & 0.34 & 0.13 & 5.44 & 5.17 & 7.79 & 4.08 \\
\hline
\end{tabular}


TABLE 5 (continuation) — Average behavior in all games

\begin{tabular}{|c|c|c|c|c|c|c|c|c|}
\hline $\begin{array}{l}\text { Treat- } \\
\text { ment } \\
\text { [share] }\end{array}$ & Game & mean $(\mathrm{sd})$ & $\begin{array}{c}\text { share } \\
\text { ten }\end{array}$ & $\begin{array}{c}\text { share } \\
\text { zero }\end{array}$ & $\begin{array}{c}\text { mean } \\
d^{+} \text {-type } \\
{[0.36]}\end{array}$ & $\begin{array}{c}\text { mean } \\
r^{+} \text {-type } \\
{[0.41]}\end{array}$ & $\begin{array}{c}\text { mean } \\
\text { selfish } \\
{[0.31]}\end{array}$ & $\begin{array}{c}\text { mean } \\
\text { maximin } \\
{[0.10]}\end{array}$ \\
\hline P32 & 1 & $2.43(2.63)$ & 0.05 & 0.40 & 2.94 & 3.19 & 0.00 & 4.00 \\
\hline P32 & 2 & $2.16(2.18)$ & 0.00 & 0.40 & 2.61 & 3.06 & 0.00 & 5.00 \\
\hline P32 & 3 & $1.96(2.45)$ & 0.01 & 0.51 & 2.35 & 2.79 & 0.00 & 6.26 \\
\hline P32 & 4 & $5.37(4.01)$ & 0.36 & 0.20 & 6.49 & 5.15 & 7.93 & 3.26 \\
\hline P32 & 5 & $4.89(3.99)$ & 0.29 & 0.25 & 5.87 & 4.52 & 7.51 & 2.22 \\
\hline P32 & 6 & $4.19(3.89)$ & 0.23 & 0.30 & 5.03 & 3.92 & 6.56 & 2.22 \\
\hline P32 & 7 & $4.59(4.10)$ & 0.26 & 0.27 & 6.33 & 4.32 & 7.39 & 2.09 \\
\hline P32 & 8 & $5.24(4.18)$ & 0.33 & 0.27 & 7.20 & 5.27 & 7.86 & 2.36 \\
\hline P32 & 9 & $6.81(4.08)$ & 0.56 & 0.16 & 8.60 & 6.70 & 8.93 & 3.64 \\
\hline P32 & 10 & $3.05(2.75)$ & 0.06 & 0.32 & 4.10 & 4.61 & 1.69 & 4.21 \\
\hline P32 & 11 & $3.25(2.82)$ & 0.05 & 0.32 & 4.33 & 4.94 & 1.79 & 5.05 \\
\hline P32 & 12 & $3.32(3.10)$ & 0.04 & 0.38 & 4.80 & 5.06 & 1.85 & 5.74 \\
\hline P32 & 13 & $3.47(2.77)$ & 0.02 & 0.31 & 4.17 & 5.08 & 2.43 & 5.08 \\
\hline P32 & 14 & $4.88(3.41)$ & 0.09 & 0.26 & 5.90 & 6.76 & 2.57 & 6.58 \\
\hline P32 & 15 & $5.59(3.69)$ & 0.13 & 0.23 & 6.77 & 7.35 & 2.93 & 8.17 \\
\hline P32 & 16 & $5.39(3.55)$ & 0.28 & 0.13 & 6.33 & 5.43 & 7.52 & 3.75 \\
\hline P32 & 17 & $5.72(3.48)$ & 0.29 & 0.14 & 6.87 & 5.84 & 7.72 & 4.42 \\
\hline P32 & 18 & $5.63(3.68)$ & 0.30 & 0.15 & 6.60 & 5.76 & 7.79 & 5.08 \\
\hline
\end{tabular}

Note: This table displays the average behavior in all games and treatments. Column 3 shows the mean provision of all subjects (standard deviation in brackets). Column 4 shows the share of subjects who provide the maximum amount (10 units). Column 5 shows the share of subjects who provide nothing. Columns 6 and 7 show the mean provision of those subjects we classify as $d^{+}$and $r^{+}$-types, respectively. Columns 8 and 9 show the mean provision of those subjects we classify as selfish and maximin types, respectively. For each treatment, in the first row, we indicate the share of $d^{+}$-types, $r^{+}$-types, selfish and maximin types. 